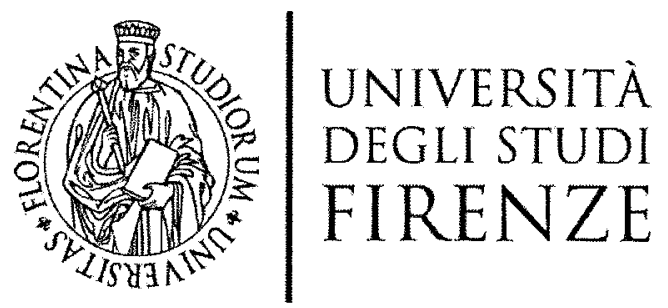

\author{
DOTTORATO DI RICERCA IN \\ AREA DEL FARMACO E TRATTAMENTI INNOVATIVI \\ CICLO XXXII
}

COORDINATORE Prof. Elisabetta Teodori

\title{
Functional validation of genetic variants identified by next generation sequencing in malformations of cortical development
}

Settore Scientifico Disciplinare MED/39

Dottorando

Dott. Dalila De Vita

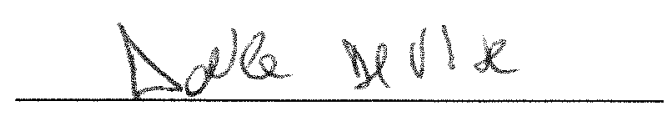

Coordinatore

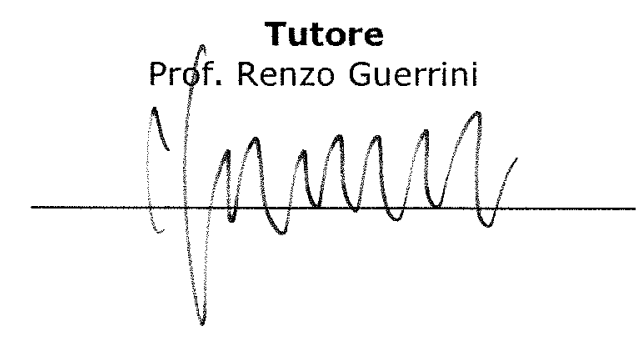

Prof. Elisabetta Teodori

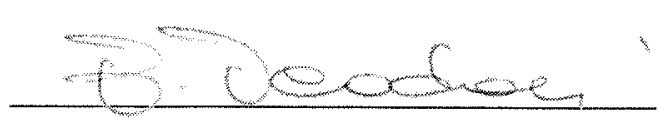




\section{ABSTRACT:}

Malformations of cortical development (MCDs) result from a disruption in the complex process of the human brain cortex formation and are highly associated to severe epilepsy, neurodevelopmental delay and motor dysfunction. The advent of next-generation sequencing (NGS) has considerably accelerated the identification of MCDs causing genes, greatly increasing their number and related knowledge. So far, more than 100 genes have been associated with one or more types of MCD. However, despite NGS technologies have considerably increased the potential of identifying the causal mutations in patients with MCD, in some cases NGS results have some limits of interpretation and functional studies are needed to clarify the role of some genetic variants. Currently, there are no treatments for diffuse MCDs, while for focal malformations, which include FCD and HME, the treatment of choice is epilepsy surgery, which is however applicable only to a subset of patients. Recently, a series of clinical trials on patients and in vivo and in vitro studies in cellular and animal models have demonstrated that pharmacological rescue of PI3K/AKT/mTOR pathway dysregulation represents a novel promising treatment option for FCD/HME. In patients carrying mutations in mTOR pathway genes, the use of first generation mTOR inhibitors (known as rapalogs) might represent an example of personalized treatment based on the knowledge of the etiological cause of the disease. Although the use of rapalogs in various clinical trials have validated the concept that targeting PI3K/Akt/mTOR has a potential therapeutic effect, patients need treatment reduction or discontinuation due to severe adverse events. Metformin, a drug widely used to treat type 2 diabetes, has been recently shown to activate the AMPactivated protein kinase (AMPK) and inhibit the mTOR pathway, causing a reduction in protein synthesis and cellular proliferation.

The aim of this $\mathrm{PhD}$ project has been to apply a multidisciplinary approach to identify causative mutations in two patients with MCDs, validate the pathogenic role of the identified mutations, and assess the effectiveness of metformin in rescuing the phenotype induced by one of the two mutations.

The first mutation (Trp219Arg missense mutation in the LIS1 gene) was identified in a male patient (Patient 1) with delay of expressive language, intellectual and motor developments and pachygyria. The patient inherited the mutation from his affected mother. In literature, it has been demonstrated that missense substitutions in LISI have variable impact on the protein in terms of folding, protein-protein interactions, and stability and are linked to an equally variable phenotypic severity. For this reason, to explore if the mutation we observed impaired one of these processes, we performed a LISI gene expression study by qPCR, which detected no significant differences between proband, mother and controls and western blot analysis, which detected normal levels of the LIS1 protein in the proband and in his mother compared to controls. Therefore, the p.Trp219Arg mutation alters neither qualitative nor quantitative LIS1 expression and does not appear to cause defective folding and degradation of the mutant protein. These results suggest that the p.Trp219Arg mutation might instead cause mildly defective protein-protein interactions, resulting in a mild phenotype. They also suggest that different extents of impairment of this mechanism might contribute to the considerable phenotypic variability observed among individuals with LIS1 missense variants. 
The second mutation (p.Thr1977Ile mosaic missense mutation in the mTOR gene), was identified in a male patient (Patient 2) who presented profound intellectual disability, megalencephaly (+2.5 SD), cutaneous pigmentary mosaicism, bilateral frontal-parietal-insular polymicrogyria, and focal epilepsy. In our patient, the mutation was somatic and was present with different percentages of mosaicism in the different tissues we tested. Since we detected the mutation also in patient's fibroblasts, a cell line easily accessible, we tested the effectiveness of a novel potential mTOR pathway inhibitor in such cells. To confirm that the mutation affected the regulation of mTOR pathway in patient's fibroblasts in response to nutrients deprivation, we evaluated the levels of P-RPS6 (direct downstream effector of mTOR protein) expression in cells incubated with a balanced salt solution used to induce starvation in fibroblasts. We observed an increased activation of the pathway caused by the gain-of-function effect of the mutation. In order to rescue of PI3K/AKT/mTOR pathway dysregulation induced by the p.Thr1977Ile mTOR mutation, we treated patient's and control's cells with metformin, demonstrating that this treatment is able to revert mTOR pathway hyperactivation.

Overall, the results we obtained point to the growing need to associate NGS analysis with rapid and effective tests in order to validate the causative effect of the identified mutations. In addition, we demonstrated that for mTOR related MCDs, patients' fibroblasts may represent a good model to test novel pharmacological treatments. 


\section{INDEX:}

1. INTRODUCTION..................................................................4

1.1 Malformations of cortical Development (MCDs)....................................

1.1.1 Lissencephaly and Subcortical Band Heterotopia.................................5

1.1.2 Tubulinopathies and Related Disorders.........................................8

1.1.3 Neuronal Heterotopia.............................................................9

1.1.4 Polymicrogyria..................................................................11

1.1.5 Megalencephaly, Hemimegalencephaly and Focal Cortical Dysplasia............12

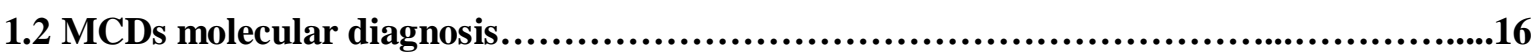

1.3 Possible treatments for MCDs.........................................................16

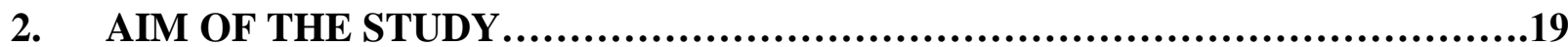

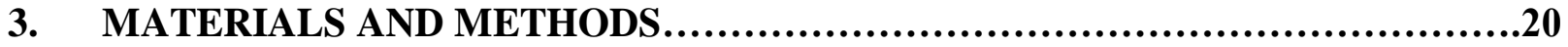

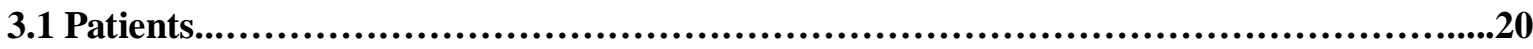

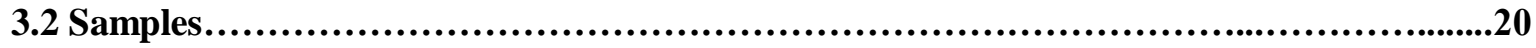

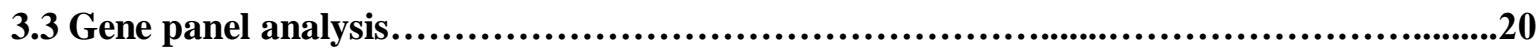

3.4 Starvation protocol on skin fibroblast culture..............................................20

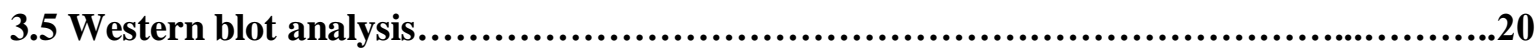

3.6 Reverse transcriptase-PCR analysis and quantitative Real-Time PCR analysis (qPCR) 22

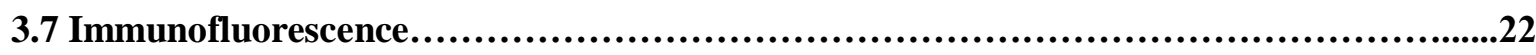

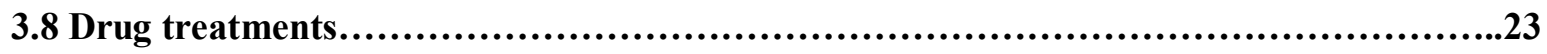

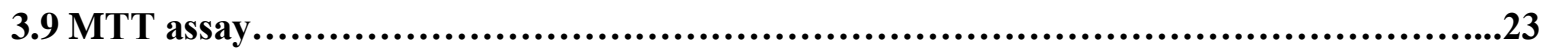

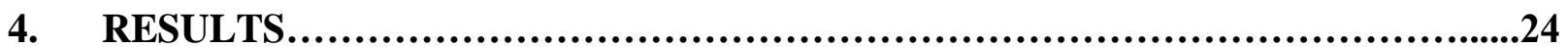

4.1 Clinical findings and gene panel analysis..........................................24

4.2 Functional validations of identified mutations on patients' samples......................27

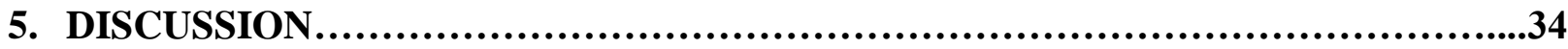

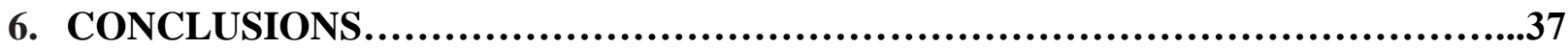

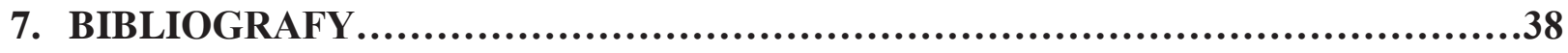




\section{INTRODUCTION}

\subsection{Malformations of cortical Development (MCDs)}

The development of the human cerebral cortex is a complex and tightly regulated process that occurs during several gestational weeks and can be divided into three steps: neural stem cell proliferation and cell type differentiation, neuronal migration, and neuronal positioning and development of cortical organization and connectivity (Gleeson et al., 2014). The disruption of any one of these processes may result in a wide range of developmental brain disorders that are designated as malformations of cortical development (MCD) which may be restricted to discrete cortical areas or may, alternatively, be diffuse. These disorders are recognized as a cause of developmental disabilities and epilepsy (Guerrini et al.2005).

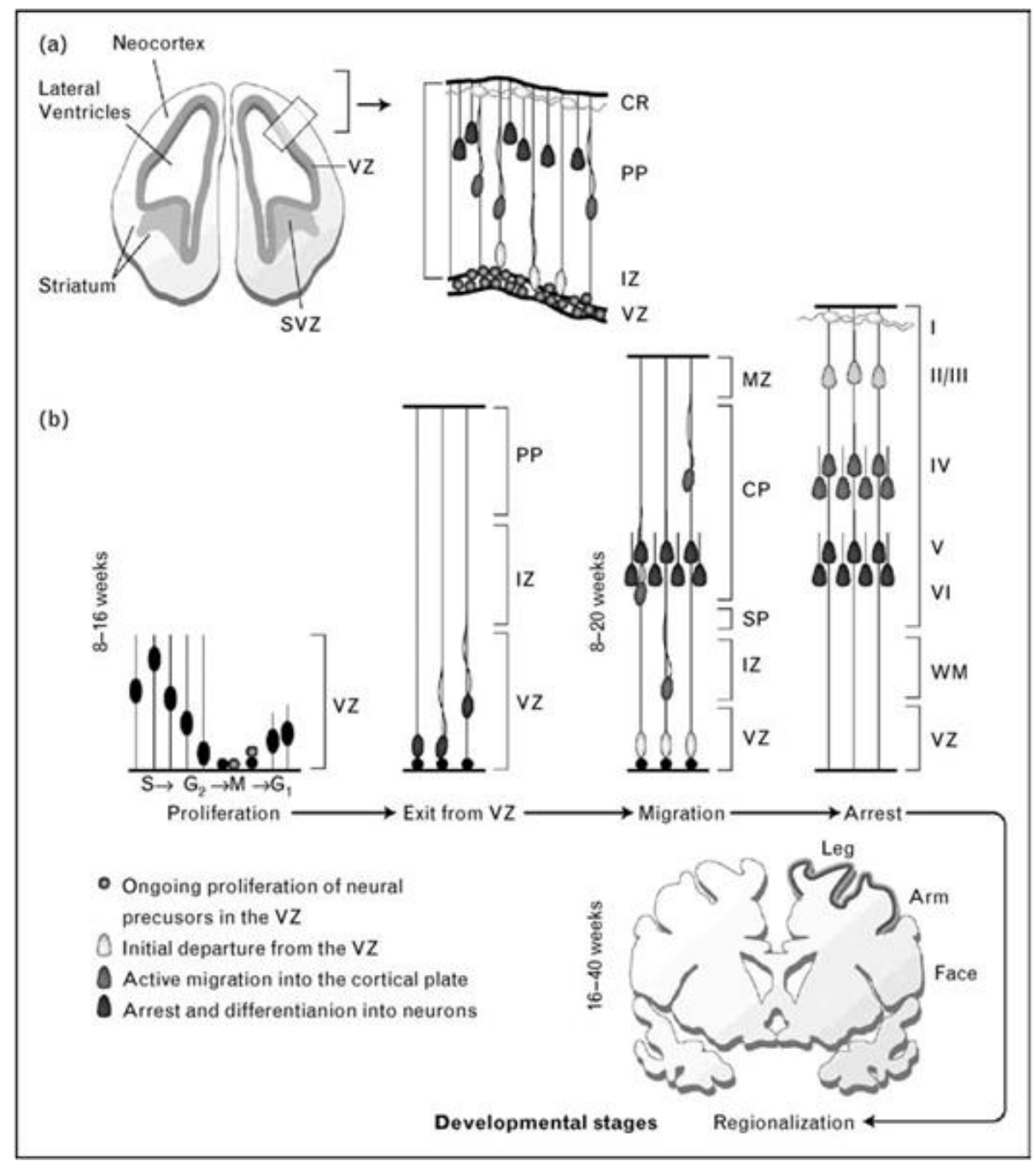

Figure 1: Phases of brain development that include cell proliferation in the ventricular zone (VZ), migration to the cortical plate (CP), arrest of migration, differentiation in different cellular subtypes and regionalization (from Da Sheen \& Walsh 2003). 
So far, more than 100 genes have been associated with one or more types of MCD. Disrupted pathways include cell-cycle regulation at many steps (especially mitosis and cell division), apoptosis, cell-fate specification, cytoskeletal structure and function, neuronal migration and basement-membrane function, and many inborn errors of metabolism. A subset of MCD genes - especially those associated with megalencephaly - are associated with postzygotic (i.e., mosaic) mutations in genes of the MTOR pathway (Lee et al., 2012). Genetic testing needs accurate assessment of imaging features and familial distribution, if any, and can be straightforward in some disorders but requires a complex diagnostic algorithm in others. Because of substantial genotypic and phenotypic heterogeneity, for most MCDs a comprehensive analysis of clinical, imaging, and genetic data is needed to properly define these disorders.

\subsubsection{Lissencephaly and Subcortical Band Heterotopia}

Lissencephaly (LIS) or smooth brain and the associated malformation known as subcortical band heterotopia (SBH) are the classic malformations associated with deficient neuronal migration (Dobyns et al., 2012).

LIS is a neuronal migration disorder characterized by absent (agyria) or decreased (pachygyria) convolutions, cortical thickening and a smooth cerebral surface (Barkovich et al., 2012; Guerrini and Dobyns, 2014) (Figure 2, A). Different subtypes of LIS are readily distinguished based on the number of cortical layers affected, and include two-layered, three-layered, and four-layered forms (Forman et al., 2005). The most common, classical LIS (four-layered form), features a very thick cortex (10-20 mm vs. the normal $4 \mathrm{~mm}$ ) and no other major brain malformations. The cytoarchitecture consists of four primitive layers, including an outer marginal layer which contains Cajal-Retzius neurons (layer 1), a superficial cellular layer, which contains numerous large and disorganized pyramidal neurons (layer 2) corresponding to the true cortex, a variable cell sparse layer (layer 3), and a deep cellular layer (composed of medium and small neurons) which extends more than half the width of the mantle (layer 4) (Golden and Harding, 2004).

$S B H$ is a related disorder in which bands of grey matter are interposed in the white matter between the cortex and the lateral ventricles (Guerrini and Parrini et al., 2010) (Figure 2, B). Histopathology demonstrates that heterotopic neurons settle close to the cortex in a pattern suggestive of laminar organization. 

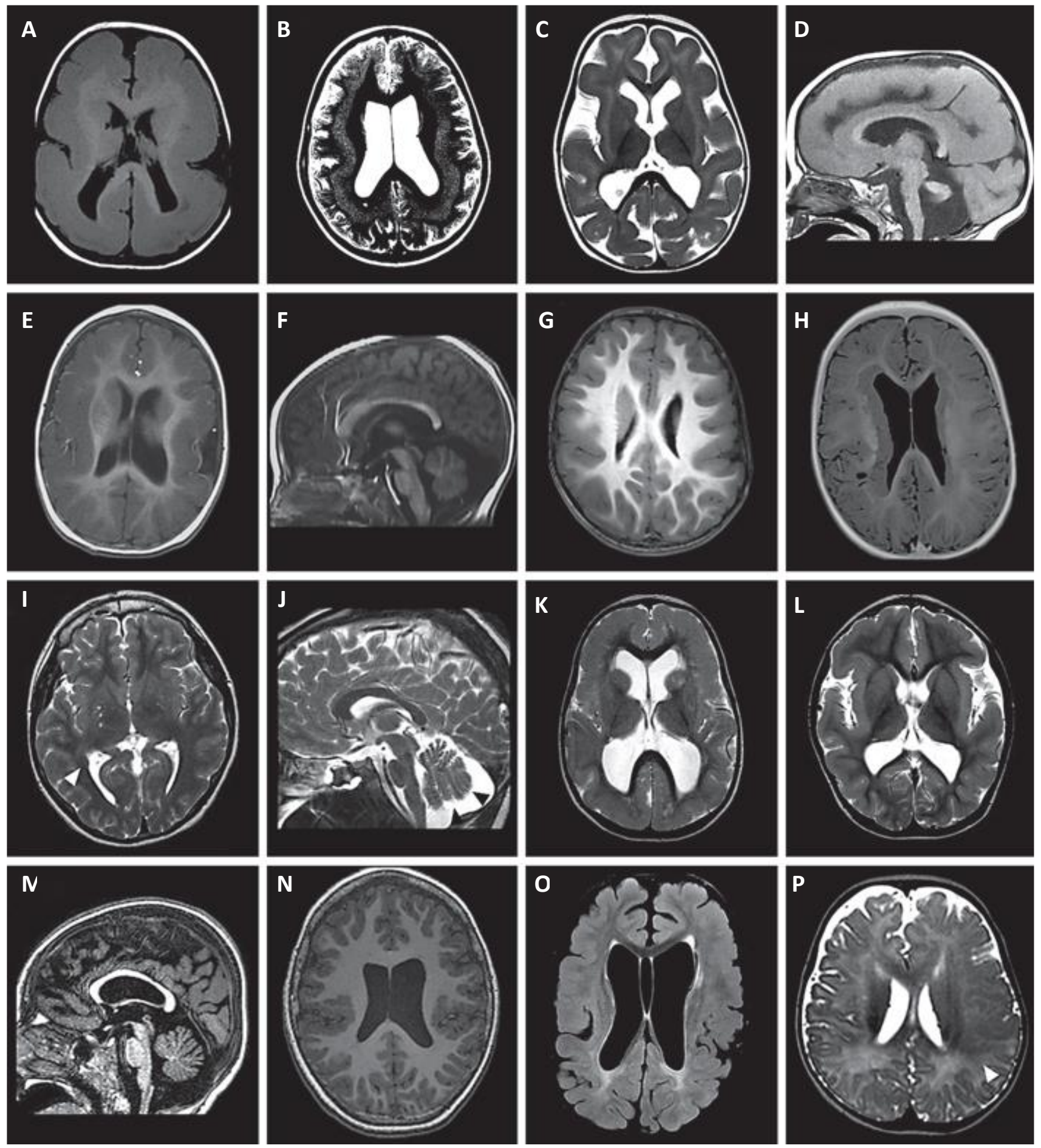

Figure 2: Brain MRI of patients with different malformations of the cerebral cortex. A T1-weighted axial section. Posterior to anterior pachygyria in a boy with LIS1 mutation. B T2-weighted axial section. Diffuse SBH in a girl with $D C X$ mutation. C, D T2weightedaxial section and T1-weighted sagittal section. Lissencephaly and cerebellar hypoplasia in a girl with RELN mutation. E, F T1-weightedaxial section and T1-weighted sagittal section. Thickened cortex with simplified gyral pattern and cerebellar hypoplasia in a girl withTUBA1A mutation. G T1-weighted axial section. Diffuse simplified gyral pattern with prominent thickening and infolding of the sylvian fissures in a boy with TUBB2B mutation. H T1-weighted axial section. Typical, classical bilateral PNH in a girl with an FLNA mutation. Bilateral nodules of subependymal heterotopia are contiguous and rather symmetric, extensively lining the ventricular walls. I, J T2-weighted axial section showing mild colpocephaly with unilateral PNH (white arrowhead) and T2weighted sagittal section through the midline, showing cerebellar vermis hypoplasia (black arrowhead) with mega cisterna magna in a patient carrying a deletioni $\mathrm{n}$ the $6 \mathrm{q} 27$ chromosomal region. $\mathbf{K}$ T2-weighted axial section. Bilateral frontoparietal polymicrogyria in a boy with GPR56 mutation. L, M T2-weighted axial section and T1-weighted coronal section. Pachygyria and perisylvian polymicrogyria in a girl with $D Y N C 1 H 1$ mutation. $\mathbf{N}$ Axial T1-weighted section in a patient with a mosaic PIK3R2 mutation. $\mathbf{O}, \mathbf{P}$ T1-weighted and T2-weighted axial images form patients carrying mosaic mutations in the MTOR gene with different percentages of mosaicism [O: p.Thr1977Ile, 20\% of mosaicism in blood, P: p.Ser2215Phe, 5.5\% of mosaicism in dysplastic brain tissue) showing bilateral cortical dysgyria $(\mathbf{O})$ and focal cortical dysplasia (P, white arrowhead)]. (from Parrini et al., 2016) 
Children with the most common types of LIS (or SBH) typically appear normal as newborns. Most affected children come to medical attention during the first year of life due to neurological deficits in the first weeks or months [Barkovich et al., 2012]. The major medical problems encountered are ongoing feeding problems and epilepsy of many different types that are often intractable. Classical LIS is rare; patients with severe LIS have early developmental delay, early diffuse hypotonia, later spastic quadriplegia, and eventual severe or profound mental retardation. Seizures occur in over $90 \%$ of LIS children, with onset before 6 months in about $75 \%$ of the cases (Guerrini and Filippi et al., 2005). Most LIS children will subsequently continue to have epileptic spasms in association with other seizure types. The EEGs show diffuse, high amplitude, fast rhythms, which are considered highly specific for this malformation. The main clinical manifestations of SBH are mental retardation and epilepsy (Barkovich et al., 1994). Epilepsy is present in almost all patients and is intractable in about $65 \%$ of the cases: about $50 \%$ of these epilepsy patients have focal seizures, and the remaining 50\% have generalized epilepsy (Parrini et al., 2016).

\section{Genetic basis and diagnosis}

Lissencephaly, subcortical band heterotopia, and lissencephaly with cerebellar hypoplasia are always genetic. To date, mutations in 12 lissencephaly genes have been identified, which account for roughly $90 \%$ of patients. However, two major genes have been associated with classic lissencephaly and SBH. The LISI gene causes the autosomal form of LIS (Reiner et al., 1993), while the DCX gene is X-linked (des Portes et al., 1998; Gleeson et al., 1998). Although either gene can result in either LIS or SBH, most cases of classic LIS are due to deletions or mutations of LIS1 (Mei et al., 2008), whereas most cases of SBH are due to mutations of DCX (Matsumoto et al., 2001). LIS1 encodes a $45 \mathrm{kDa}$ protein (PAFAH1B1), which functions as a regulatory subunit of platelet-activating factor acetylhydrolase (PAF-AH) (Hirotsune et al.,1998). DCX encodes a $40 \mathrm{kDa}$ microtubule-associated protein (DCX) that is expressed in migrating neuroblasts (Gleeson et al., 2000). The DCX protein contains two tandem conserved repeats. Each repeat binds to tubulin and both repeats are necessary for microtubule polymerization and stabilization. LISI-related LIS is more severe in the posterior brain regions ( $\mathrm{p}>\mathrm{a}$ gradient), whereas $D C X$ related LIS is more severe in the anterior brain ( $\mathrm{a}>\mathrm{p}$ gradient). About $60 \%$ of patients with $\mathrm{p}>\mathrm{a}$ isolated LIS (ILS) carry genomic alterations or mutations involving LIS1 (Mei et al., 2008). A simplified gyral pattern in the posterior brain, with underlying SBH, has been associated with mosaic mutations of LIS1 (Sicca et al., 2003). Most DCX mutations cause a>p $\mathrm{SBH} /$ pachygyria. Mutations of $D C X$ have been found in all reported pedigrees and in $80 \%$ of sporadic females and $25 \%$ of sporadic males with SBH (Matsumoto et al., 2001). Genomic deletions of the DCX gene have been identified in females with sporadic SBH and in males with X-linked lissencephaly (Mei et al., 2007). Maternal germline or mosaic DCX mutations may occur in about $10 \%$ of cases of either SBH or Xlinked lissencephaly (Gleeson et al., 2000b). Hemizygous males with $D C X$ mutations have classical LIS, but rare boys with missense mutations and anteriorly-predominant $\mathrm{SBH}$ and rare females with DCX mutations and normal brain MRI have been described (Guerrini et al.,2003). Autosomal recessive lissencephaly with cerebellar hypoplasia consists of mild frontal predominant lissencephaly, plus severe hippocampal and 
cerebellar hypoplasia and dysplasia. This pattern has been associated with mutations in RELN (Hong et al., 2000) or VLDLR (an essential cell-surface receptor for reelin) (Figure 2, C-D) (Boycott et al., 2005). Many patients with $A C T B$ and $A C T G 1$ mutations show pachygyria with a>p severity gradient, similar to that observed in males with $D C X$ mutations (Riviere et al.,2012; Verloes et al., 2015). A mutation in the $C D K 5$ gene has been identified in four individuals with lissencephaly and cerebellar hypoplasia born from a highly consanguineous family (Magen et al., 2015). In patients with classic lissencephaly, cytogenetic and molecular investigations are part of the diagnostic process. When isolated lissencephaly is diagnosed, careful assessment of the antero-posterior gradient of the abnormal cortical pattern will suggest whether to investigate LISI or DCX. When lissencephaly is more severe posteriorly, it is worth performing first MLPA to rule out LISI deletions/duplications. If a deletion/duplication is not found, LISI sequencing should then be performed. In boys whose MRI shows more severe pachygyria in the frontal lobes, sequencing of the $D C X$ gene is indicated. In patients with SBH direct sequencing of $D C X$ should be performed. If a $D C X$ mutation is not found, MLPA analysis then should be performed. Direct sequencing is also indicated in the mothers of patients harbouring a $D C X$ mutation or other female relatives. Analysis of the ACTB and ACTG1 genes should be performed in patients with frontal predominant pachygyria who are not harbouring $D C X$ mutations.

Most reported LIS1 alterations are de novo: given the theoretical risk of germline mosaicism in either parent (which has never been demonstrated for LIS1), a couple with a child with lissencephaly is usually given a $1 \%$ recurrence risk. However, recently, Mineyko et al. described a male with pachygyria who inherited a novel LIS1 gene mutation from the mother with somatic mosaicism. (Mineyko et al., 2016) In addition, we identified a mother and son with focal epilepsy, mild cognitive impairment, and pachygyria, carrying a novel constitutional missense variant in the LIS1 gene, segregating in the proband and in his mother.

When a $D C X$ mutation is found in a boy with lissencephaly, mutation analysis of $D C X$ should be extended to the proband's mother, even if her brain MRI is normal. If the mother is a mutation carrier, the mutation will be transmitted according to Mendelian inheritance. If the mother is not a carrier, there still is a risk of germline mosaicism, which is roughly estimated at around $5 \%$.

\subsubsection{Tubulinopathies and Related Disorders}

Mutations of tubulin genes were first reported as causing lissencephaly (for TUBA1A) (Keayset al., 2007) or polymicrogyria (PMG) (for TUBB2B) (Jaglin et al., 2009). However, the cortical malformations seen in most individuals with mutations of tubulin or tubulin motor genes comprise a wide spectrum of morphological abnormalities whose characteristics are at times distinctive but can also overlap with those of lissencephaly and polymicrogyria by brain imaging and neuropathology (Cushion et al., 2013; Poirier et al., 2013). The full range of these malformations vary from extreme lissencephaly with completely absent gyri, total agenesis of the corpus callosum, and severe cerebellar hypoplasia, to less severe lissencephaly with moderate-to-severe cerebellar hypoplasia, to classic lissencephaly, to an atypical polymicrogyria-like cortical malformation with cerebellar hypoplasia (Cushion et al., 2013; Poirier et al., 2013). Cortical thickness varies and can be mildly 
thin, normal or mildly thick. Most children with mutations of tubulin genes have severe intellectual disability and intractable seizures.

\section{Genetic basis and diagnosis}

Nine genes (KIF2A, KIF5C, TUBA1A, TUBA8, TUBB, TUBB2B, TUBB3, TUBG1 and DYNC1H1) associated with tubulinopathies have been identified so far (Bahi-Buisson et al., 2014). Findings from functional studies suggest that abnormal brain development in tubulinopathies results from a dominant negative effect of heterozygous missense mutations (in the absence of loss-of-function mutations) on the regulation of microtubule-dependent mitotic processes in progenitor cells, and on the trafficking activities of the microtubule-dependent molecular motors KIF2A, KIF5C, and DYNC1H1 in post-mitotic neuronal cells (Poirier et al., 2013). Heterozygous missense mutations of TUBA1A have been found in this syndrome, with TUBA1A accounting for $\sim 30 \%$ of patients (Kumar et al., 2010; Cushion et al., 2013) (Figure 2, E-F-G). Testing is available for all of the tubulin and tubulin motor genes so far identified. For all but TUBA8, only de novo heterozygous missense mutations have been found. The phenotype (if any) associated with truncation or deletion mutations of most of the tubulin genes is unknown. Probably, these genes are intolerant to loss of function mutations, as also suggested by the observation that in the ExAC Database (http://exac.broadinstitute.org/), the tubulin genes, with the exception of $T U B A 8$, have a probability of loss of function intolerance (pLI) near to 1.00, a value consistent with an almost complete intolerance. A single family with a tubulinopathy phenotype has been reported with a homozygous mutation of TUBA8 (Abdollahi et al., 2009).

\subsubsection{Neuronal Heterotopia}

There are three main groups of heterotopia: periventricular (usually nodular: $\mathrm{PNH}$ ), subcortical and leptomeningeal (glioneuronal heterotopia found over the surface of the brain), of which only the first two can be detected by imaging. PNH is by far the most frequent. SBH is a mild form of LIS and has been dealt with previously.

PNH consists of nodules of grey matter located along the lateral ventricles with a total failure of migration of some neurons (Barkovich et al., 2012; Guerrini and Dobyns, 2014); it ranges from isolated, single, to confluent bilateral nodules (Figure 3, H). The overlying cortex may show an abnormal organization. When the nodules are bilateral and numerous, a genetic basis is probable, and associated brain malformations are often reported (Parrini et al., 2006). Patients with the classic X-linked PNH typically have bilateral contiguous nodules that spare the temporal horns and mild cerebellar vermis hypoplasia with mega cisterna magna (Parrini et al., 2006). Patients with rare autosomal recessive bilateral PNH can have severe congenital microcephaly and thin overlying cortex with abnormal gyri (Sheen et al., 2004). In the fairly common posterior predominant syndromes, PNH is limited to the trigones, temporal and occipital horns, and can be associated with overlying polymicrogyria, hippocampal and cerebellar hypoplasia, or hydrocephalus (Pisano et al., 2012). 
Although most patients with PNH come to medical attention because they have focal epilepsy of variable severity, there is a wide spectrum of clinical presentations, including several syndromes with intellectual disability and dysmorphic facial features. There is some correlation between the size of PNH and the likelihood of concomitant structural abnormality of the cortex and clinical severity (Parrini et al., 2006), but there seems to be no correlation between the size and number of heterotopic nodules and cognitive outcome or epilepsy severity. Most females with PNH due to FLNA mutations have epilepsy, with normal or borderline cognitive level. Age at seizure onset is variable. Most patients have focal seizures, which can be easily controlled or refractory (Parrini et al., 2006). There is no clear relationship between epilepsy severity and the extent of nodular heterotopia.

\section{Genetic Basis and Diagnosis}

The most common syndromic form of PNH (X-linked PNH) consists of bilateral contiguous or near contiguous nodules and is most often caused by FLNA mutations. All other PNH syndromes are rare.

$\mathrm{X}$-linked PNH is a clinically and genetically heterogeneous disorder occurring most frequently in women, associated with high rates of prenatal lethality in male foetuses, and a 50\% recurrence risk in the female offspring. Almost $100 \%$ of the families and $26 \%$ of sporadic patients harbor mutations in the FLNA gene (Parrini et al., 2006), which also causes cardiovascular abnormalities in some patients of both sexes and gut malformations in boys. Only a few male patients with PNH owing to FLNA mutations have been reported (Guerrini et al., 2004). FLNA encodes a large actin-binding phosphoprotein that stabilizes the cytoskeleton and contributes to the formation of focal adhesions along the ventricular epithelium [Fox et al., 1998]. FLNA may be required for the initial attachment of neurons onto the radial glial scaffolding before migration from the ventricular zone ( $\mathrm{Lu}$ et al., 2006). Failure of migrating neurons to attach to radial glia is one likely mechanism leading to the formation of heterotopia. A rare recessive form of PNH owing to mutations of the ARFGEF2 gene was described in two consanguineous pedigrees (Sheen et al., 2004) in which affected children had microcephaly, severe cognitive delay, and early-onset seizures. Other genetic forms of PNH have been associated with chromosomal rearrangements, in particular 6q27deletion (Figure 2, I-J) including C6orf70 (also known as ERMARD) mapping in 6q27, and a few additional putative causal genes (EML1, FAT4 and DCHS1) (Cappello et al., 2013; Conti et al., 2013; Kielar et al.,2014).

FLNA mutation analysis should be performed in patients with 'classical' bilateral PNH. When PNH is associated with microcephaly, the autosomal recessive form caused by ARFGEF2 mutations should be ruled out. Patients with PNH associated with other brain malformations or extra neurological defects, should be studied with array-CGH. Classical PNH is much more frequent in women and likely to be caused by FLNA mutations. Among carrier women, about half have de novo FLNA mutations, whereas the remaining have inherited mutations. Although maternal transmission is much more likely, father-to-daughter transmission is possible. Given that germline mosaicism of FLNA has never been reported, the recurrence risk (for other children) seems to be very low when a mutation is found in the proband but neither parent is a carrier. 
Counselling is very difficult when PNH is not related to either FLNA or ARFGEF2, and array-CGH study is advised. Familial PNH unrelated to these genes is exceptionally low.

\subsubsection{Polymicrogyria}

The term polymicrogyria defines an excessive number of abnormally small gyri that produce an irregular cortical surface with a lumpy aspect (Bielschowsky, 1916). Polymicrogyria can be limited to a single gyrus, involving a portion of one hemisphere, be bilateral and asymmetrical, bilateral and symmetrical, or diffuse. Sometimes, it is associated with deep clefts that may extend through the entire cerebral mantle to communicate with the lateral ventricle (schizencephaly) (Barkovich and Kjos et al., 1992). Macroscopically, polymicrogyria appears as an irregular or pebbled cortical surface. The perisylvian cortex is the most frequently affected. The cortex often appears thickened to $8-12 \mathrm{~mm}$, but when viewed microscopically, it is overfolded and not necessarily thick. While polymicrogyria most often occurs as an isolated malformation, it can occur with several other brain malformations, including microcephaly, megalencephaly, grey matter heterotopia, ventriculomegaly as well as abnormalities of the septum pellucidum, corpus callosum, brainstem and cerebellum. When schizencephaly is present, the cortex edges can seem to fuse (closed lips) or stay at distance (open lips). The clefts of schizencephaly can be unilateral or bilateral. An area of polymicrogyria can occur in the cortex contralateral to a unilateral cleft (Yakovlev and Wadsworth, 1946).

Using CT and low-field strength MRI, polymicrogyria is difficult to discern and may only appear as a mildly thickened, irregular cortex. For this reason, polymicrogyria is frequently misdiagnosed as pachygyria or LIS. The imaging appearance of polymicrogyria varies with the patient's age. In newborns and young infants, the malformed cortex is very thin with multiple, very small undulations. After myelination, polymicrogyria appears as thickened cortex (usually 6-10 mm) with irregular cortex-white matter junction. In schizencephaly, the grey matter lining the cleft has the imaging appearance of polymicrogyria with an irregular surface, deep infolding (the cleft), mildly thick cortex, and stippling of the interface between grey and white matter. Schizencephaly is often bilateral but frequently asymmetrical; the contralateral hemisphere should be closely assessed for milder clefts or polymicrogyria without cleft (Barkovich and Kjos, 1992). Polymicrogyria has been described in a number of topographic patterns. Most of these are bilateral and symmetrical, the most common of which is bilateral perisylvian polymicrogyria, although the perisylvian form maybe asymmetric or unilateral. Other bilateral symmetric forms are generalized, bilateral frontal, and parasagittal parieto-occipital polymicrogyria (Guerrini et al., 1997; Barkovich et al., 1999; Leventer et al., 2010), although little or no neuropathological data is available to support the classification.

The clinical manifestations of polymicrogyria vary widely and depend on several factors. The most severe outcomes occur in children with severe microcephaly (-3 SD or smaller), abnormal neurological examination, widespread anatomic abnormality, and additional brain malformations such as heterotopia or cerebellar hypoplasia. The best outcomes are in individuals who have localized unilateral polymicrogyria without other malformations. Polymicrogyria can affect eloquent cortical areas representing language or primary motor functions, yet these functions can be retained with little or no disability (Guerrini and Barba, 
2010). Bilateral perisylvian polymicrogyria is associated with mild to moderate intellectual disability, epilepsy, and impaired or motor skills. More severely affected patient shave minimal or no expressive speech. The frequency of epilepsy in these patients is $60-85 \%$, although seizure onset may not occur until the second decade, usually between 4 and 12 years of age (Kuzniecky et al., 1993; Barkovichet al., 1999). Patients with closed-lip schizencephaly typically present with hemiparesis or motor delay, whereas patients with open-lip schizencephaly typically present with hydrocephalus, seizures and intellectual disability, which can be severe (Packard et al., 1997). Seizure types include infantile spasms, complex partial seizures as well as tonic, atonic, and tonic-clonic seizures, although these are less common.

\section{Genetic Basis and Diagnosis}

Numerous causes, both genetic and non genetic, have been associated with polymicrogyria. Non genetic causes other than hypoxia or hypoperfusion relate mainly to congenital infections, primarily cytomegalovirus (Evrard et al., 1989; Barkovich and Lindan et al, 1994). Polymicrogyria is associated with a wide number of patterns and syndromes as well as mutations in several genes: various types of single-gene inheritance have been hypothesized for polymicrogyria, based on observations of families with X-linked (Guerreiro et al., 2000; Villard et al., 2002; Santos et al., 2008), autosomal dominant (Guerreiro et al., 2000; Chang et al., 2006), and autosomal recessive forms (Hilburger et al., 1993; Guerreiro et al., 2000). Bilateral frontoparietal polymicrogyria, (fig. $1 \mathrm{~K}$ ) has been associated with mutations in the GPR56 gene in families with recessive pedigrees (Piao et al., 2004). Polymicrogyria occurs with a few types of severe congenital microcephaly, such as autosomal recessive syndromes associated with mutations in the WDR62 (Bilgüvar et al., 2010), NDE1 (Alkuraya et al., 2011), or KATNB1 (Mishra-Gorur et al., 2014) genes. Polymicrogyria with microcephaly or normal head size has been reported with several tubulin and tubulin motor genes, especially TUBB2B (Figure 2, G) (Jaglin et al., 2009; Guerrini et al., 2012) and DYNC1H1 (Figure 2, L, M) (Poirier et al., 2013). Autosomal recessive forms of polymicrogyria have been linked to mutations of RTTN (Kheradmand Kia et al., 2012). Also, polymicrogyria has now been reported in several megalencephaly syndromes. Recently, it has been demonstrated that mutations in PIK3R2, a pivotal gene of the PI3K-AKTmTOR pathway, may account for up to $15 \%$ of all patients with bilateral perisylvian polymicrogyria with or without megalencephaly (Figure 2, N) (Mirzaa et al., 2015). Some copy-number variants have been associated with polymicrogyria, but only deletions in 1p36.3 and 22q11.2 are common (Robin et al., 2006; Dobyns et al., 2008). Indeed, when these 2 loci are excluded, copy number variants seem to be rare. A causal gene has not been identified for any of these loci.

\subsubsection{Megalencephaly, Hemimegalencephaly and Focal Cortical Dysplasia}

The term megalencephaly refers to an abnormally large brain that exceeds the mean for age and gender by 2SD (De Myer, 1986). Megalencephaly has most often been classified simply as a disorder of brain size, but recent studies have shown that megalencephaly with normal cortex by imaging, megalencephaly with polymicrogyria, and dysplastic megalencephaly (including classic hemimegalencephaly) as well as FCD can 
all result from mutations in genes in the PI3K-AKT-mTOR pathway (Lee et al., 2012; Poduri et al., 2012; Rivière et al., 2012). Hemimegalencephaly and FCD constitute a spectrum of malformations of cortical development with shared neuropathological features. The former is primarily defined by macroscopic enlargement of (more or less) one hemisphere, while FCD is primarily defined by histopathology. As currently classified (Blümcke et al., 2011), FCD encompasses a wide spectrum of cortical malformations with variable features, including microscopic neuronal heterotopia, dyslamination, and abnormal cell types. FCD has been divided into 3 major types and 9 subtypes based on histopathological features (Blümcke and Spreafico, 2011; Blümcke et al., 2011). Type 1 FCD is characterized by abnormal cortical lamination, type 2 FCD includes cortical dyslamination with dysmorphic neurons (2a) and balloon cells (2b), type 3 FCD occurs in combination with other brain lesions (e.g., tumors) (Blümcke et al., 2011). The histological changes in hemimegalencephaly, which can be considered as an extreme hemispheric form of FCD, are similar, if not identical, to FCD type 2, with cortical dyslamination and dysmorphic neurons, without (type 2a) or with (type 2 b) balloon cells, blurred junctions between grey and white matter, and increased heterotopic neurons in white matter (De Rosa et al.,1992; Blümcke et al., 2011; Guerrini et al., 2015).

The most common cortical malformation in megalencephaly is perisylvian polymicrogyria that looks very similar to perisylvian polymicrogyria in patients with normal or small head size. The cortical changes in hemimegalencephaly are severe and consist of an enlargement of part or a complete hemisphere (or less often bilateral asymmetrical involvement) with no consistent preference for which lobes of the brain are enlarged (Salamon et al., 2006).

The developmental and health complications of megalencephaly differ widely. The most common problems include developmental delay, intellectual disability, and seizures that can start early in life and be intractable. Children with diffuse symmetrical or mildly asymmetrical megalencephaly, with or without associated polymicrogyria, have a large head size at birth that soon exceeds +3 SD (Mirzaa et al., 2012). Their early development is delayed, and later cognitive development varies from normal to severe intellectual disability. Seizures can begin at any time in childhood. Epilepsy usually begins in the first weeks or months of life and can include infantile spasms and other epileptic encephalopathies. The most common clinical sequelae of FCD are seizures. Developmental delay, cognitive disability, and focal neurological deficits are only observed with extensive dysplasias. Early seizure onset has been associated with infantile spasms with asymmetrical or focal features (Guerrini and Filippi, 2005).

\section{Genetic Basis and Diagnosis}

Megalencephaly without cortical malformations occurs in benign autosomal dominant macrocephaly, a poorly defined disorder. Megalencephaly with polymicrogyria occurs in megalencephaly-capillary malformation syndrome (with mutations of PIK3CA) and megalencephaly-polymicrogyria polydactylyhydrocephalus syndrome (with mutations of PIK3R2 or AKT3) (Mirzaa et al., 2012). Hemimegalencephaly most often occurs without syndromic features, and has recently been associated with mosaic mutations of PIK3CA, AKT3, and MTOR (Figure 2, O-P). (Lee et al., 2012) Hemimegalencephaly has also been associated 
with tuberous sclerosis (D'Agostino et al., 2004; Tinkle et al., 2005). The highly focal and variable nature of FCD type $2 b$, and the pathological resemblance to tubers in tuberous sclerosis, led to the hypothesis that somatic mosaic mutations of genes that encode proteins in the PI3K-AKT-mTOR pathway, which includes the tuberous sclerosis associated genes TSC1 and TSC2, were implicated in FCD (Crino, 2009). This hypothesis has been in part confirmed by studies documenting pathogenic germline and mosaic mutations in the $m T O R$ gene or in other genes belonging to the PI3K-AKT-mTOR pathway (i.e., A KT3 , DEPDC5 , and NPRL3 ) in the dysplastic tissue of FCD type 2a and 2b (D'Gama et al., 2015; Lim et al., 2015; Sim et al., 2015). In addition, somatic duplications in the 1q chromosomal region compassing the AKT3 gene have been associated with megalencephaly, hemimegalencephaly, and FCD typelb (Poduri et al., 2012; Wang et al.,

2013; Conti et al., 2015). When performing genetic testing for disorders possibly caused by mosaic mutations, the screening of multiple tissues (e.g., blood, saliva, and skin fibroblasts) is advisable. Indeed, although testing DNA extracted from blood is the gold standard for identifying de novo constitutive mutations, the analysis of different tissues may help in identifying mutations that are only present in a subset of somatic cells (Nellist et al., 2015).

\begin{tabular}{|c|c|}
\hline Megalencephaly-polymicrogyria and dysplastic megalencephaly & Gene \\
\hline MPPH, DMEG & AKT3 \\
\hline Weaver syndrome & EZH2 \\
\hline MCAP & PIK3CA \\
\hline MPPH & PIK3R2 \\
\hline FCD Somatic & MTOR \\
\hline FCD & $D E P D C 5$ \\
\hline FCD Somatic & AKT3 \\
\hline FCD & $N P R L 3$ \\
\hline Polymicrogyria (PMG) & Gene \\
\hline Bilateral frontoparietal PMG & GPR56 \\
\hline Asymmetric PMG & $T U B B 2 B$ \\
\hline PMG and rolandic seizures, oromotor dyspraxia & SRPX2 \\
\hline PMG and agenesis of the corpus callosum (ACC), microcephaly & $T B R 2$ \\
\hline PMG and aniridia & PAX6 \\
\hline PMG and microcephaly & NDE1 \\
\hline PMG and microcephaly & WDR62 \\
\hline PMG fumaric aciduria & $F H$ \\
\hline PMG and "band-like calcfications" & $O C L N$ \\
\hline Perysilvian PMG and CHARGE syndrome & CHD7 \\
\hline PMG and Warburg Micro syndrome & $R A B 3 G A P 1$ \\
\hline PMG and Warburg Micro syndrome & $R A B 3 G A P 2$ \\
\hline PMG and Warburg Micro syndrome & $R A B 18$ \\
\hline PMG-like, microcephaly, ACC & $D Y N C l H 1$ \\
\hline PMG-like, microcephaly, ACC, CBLH & TUBAIA \\
\hline PMG-like, microcephaly, ACC, CBLH & TUBA8 \\
\hline PMG-like, microcephaly, ACC, CBLH & $T U B B 3$ \\
\hline PMG-like, microcephaly, ACC, CBLH & $T U B B$ \\
\hline
\end{tabular}


PMG-like, microcephaly, ACC

PMG and Goldberg-Shprintzen syndrome

$\mathrm{PMG}$ and $\mathrm{CK}$ syndrome

PMG and CEDNIK syndrome

SNAP29

PMG and Knobloch syndrome

COL18A1

Bilateral Perysilvian PMG

PIK3R2

Bilateral temporooccipital PMG

FIG4

PMG and microcephaly

RTTN

\begin{tabular}{|lc|}
\hline Lissencephaly (LIS) & Gene \\
MDS & LISI \\
ILS or SBH & LISI \\
ILS or SBH X-linked & $D C X$ \\
Pachygyria and Baraitser-Winter & $A C T B$ \\
Pachygyria and Baraitser-Winter & $A C T G 1$ \\
ILS or SBH & $T U B A 1 A$ \\
XLAG X-linked & $A R X$ \\
LIS cerebellar hypoplasia & $R E L N$ \\
LIS cerebellar hypoplasia & $V L D R$ \\
LIS cerebellar hypoplasia & $C D K 5$ \\
Posterior predominant pachygyria & $D Y N C 1 H 1$ \\
Posterior predominant agyria/pachygyria & KIF2A \\
ILS & $T U B A 1 A$ \\
ILS & $T U B B 2 B$ \\
Posterior predominant pachygyria & $T U B G 1$ \\
Classic LIS with variable gradient (p>a or a>p) & KIF5C \\
Periventricular nodular heterotopia (PNH) & Gene \\
Classical bilateral PNH & $F L N A$ \\
Ehlers-Danlos syndrome and PNH & $F L N A$ \\
Facial dysmorphisms, severe constipation and PNH & $F L N A$ \\
Fragile-X syndrome and PNH & $F M R 1$ \\
Microcephaly and PNH & $A R F G E F 2$ \\
Agenesis of the corpus callosum, polymicrogyria and PNH & $E R M A R D$ \\
PNH and Van Maldergem syndrome type 2 & $F A T 4$ \\
PNH and Van Maldergem syndrome type 1 & $D C H S 1$ \\
Donnai-Barrow syndrome and PNH & $L R P 2$ \\
\hline
\end{tabular}

Table 1: Most common gene involved in MCDs. Legend: $\mathrm{ACC}=$ agenesis of the corpus callosum; $\mathrm{CBLH}=$ diffuse cerebellar hypoplasia; DMEG = dysplastic megalencephaly; ILS = isolated LIS; MCAP = megalencephaly-capillary malformation syndrome; MDS = Miller-Dieker syndrome; MPPH = megalencephaly-polymicrogyria-polydactyly-hydrocephalus syndrome; PMG = polymicrogyria. 


\subsection{MCDs molecular diagnosis}

The massive parallel sequencing technology, also known as next-generation sequencing (NGS), has revolutionized the field of molecular biology allowing simultaneous screening for mutations in hundreds of loci. In NGS, fragmented DNA is amplified and sequenced in parallel, then aligned to the reference genome and evaluated for nucleotide changes and small insertions/deletions by bioinformatics software. The advent of NGS has considerably accelerated the identification of MCDs causing genes, greatly increasing their number and related knowledge (Fernández-Marmiesse et al., 2018) Accordingly, the scenario of genetic diagnostic testing has significantly changed with the application of NGS, including whole-exome sequencing (WES) and genes panels sequencing. Genes panels replace a single-gene approach with a panel of genes or gene regions that have known or suspected associations with the disease or the phenotype under study. They can be purchased with preselected or custom designed content to include genomic regions of interest (Di Resta et al., 2018). WES, instead, is not limited to selected genes but includes the exons of almost all the known human protein coding genes (about 20,000) (Bahareh Rabbani et al., 2014). The screening of multiple genes in the same experiment has the invaluable advantage of boosting new genotype-phenotype correlations and possibly identifying genetic causes of MCD for which molecular diagnosis is still missing.

However, although a broader clinical use of WES would be desirable, limitations remain that hamper its use and prefer the use of the gene panel approach due to technical reasons: by reducing the number of regions to be examined, much deeper coverage can be achieved, increasing the chances of detecting Copy Number Variations (CNVs) that involve targeted genes and detecting somatic mosaic mutation. For these reasons, the use of gene panels remains effective particularly in malformation with a focal origin.

\subsection{Possible treatments for MCDs}

Currently, there are no treatments for diffuse MCDs, while for FCD and HME the treatment of choice is epilepsy surgery, which is however only applicable to a subset of patients (Korman et al., 2013). Recently, a series of clinical trials on patients and in vivo and in vitro studies in cellular and animal models have demonstrated that pharmacological rescue of mTOR pathway dysregulation represents a novel promising treatment option for FCD/HME.

The serine/threonine kinase mTOR is at the center of signaling pathways that are critical for the regulation of cellular metabolism, growth, and proliferation (Ma XM et al., 2009). mTOR participates to the formation of two separate protein complexes: mTORC1 and mTORC2. mTORC1 is composed by mTOR, raptor, mLST8, Pras40, and Deptor (Peterson et al., 2009; Hara et al., 2002). Some of the mTORC1 components (mTOR, mLST8 and Deptor) are also present in mTORC2, which, in addition, contains several unique subunits, including Rictor, mSIN1 and PRR5 (Sarbassov et al., 2004). The best-known downstream substrates of mTORC1 are S6 kinases (S6K1 and S6K2) and 4E-BP1 (eukaryotic initiation factor 4E-binding protein-1), which are involved in protein translation (Ma XM et al, 2009). To coordinate cell growth and proliferation, mTORC1 responds not only to growth factors but also to energy, amino acids and oxygen levels (Robert A. 
et al., 2017). Activation of mTORC1 leads to the phosphorylation of S6K1, which in turn phosphorylates ribosomal S6 protein (RPS6) a component of the 40S ribosomal subunit (Choo et al., 2008). For this reason, the expression of Phospho-RPS6 (P-RPS6) is often used to monitor mTOR activity.

In patients carrying mutations in mTOR pathway genes, the use of mTOR inhibitors might represent an example of personalized treatment based on the knowledge of the etiological cause of the disease. Rapamycin and its analogs (rapalogs) are recognized as the first generation mTOR inhibitors and inhibit the activity of mTORC1 via binding to FKBP-12 and forming a ternary complex with mTOR itself. Rapalogs have the same molecular scaffold of rapamycin but different physicochemical properties. Clinical trials with different rapalogs are ongoing in a wide range of human malignancies. Temsirolimus and everolimus have been approved by the FDA for the treatment of patients with advanced renal cell carcinoma (Hudes $\mathrm{G}$ et al. 2007; Motzer RJ et al. 2008) Everolimus has also been approved as monotherapy or a component of combination therapy for pediatric and adult patients with subependymal giant cell astrocytoma (SEGA) and SEGA associated with tuberous sclerosis (TSC). Additional clinical trials to examine the effects of rapamycin on neurocognitive functions, autistic phenotypes, and epilepsy are underway (Ehninger et al., 2013). In vitro studies have demonstrated the efficacy of mTOR inhibitors in the treatment of various neurological disorders. In 2015, Lim and collaborators proved that focal cortical expression of mutant MTOR by in utero electroporation in mice was sufficient to disrupt neuronal migration and cause spontaneous seizures and the occurrence of cytomegalic neurons. Inhibition of mTOR with rapamycin suppressed epileptic seizures and reverted neuronal cytomegalic phenotype. In 2016, Mirzaa and collaborators demonstrated that increased cell size in cultured rodent neurons expressing mutant MTOR constructs could be reversed by 7 days of mTOR inhibition with the rapalog everolimus (Mirzaa et al. 2016). Although the use of rapalogs in various clinical trials have validated the concept that targeting $\mathrm{PI} 3 \mathrm{~K} / \mathrm{AKT} / \mathrm{mTOR}$ has a potential therapeutic effect, patients need treatment reduction or discontinuation due to severe adverse events. Since rapalogs suppress the immune system, patients may experience bacterial and viral infection. In addition, their use is also very frequently associated with dermatological adverse events (edema, aphthous ulcers) (Lamming et al. 2013). Rapamycin treatment may also lead to metabolic changes, including hyperlipidemia, decreased insulin sensitivity, glucose intolerance, and an increased incidence of new-onset diabetes (Gyurus et al., 2011).

Metformin, a drug widely used to treat type 2 diabetes, has been recently shown to activate the AMPactivated protein kinase (AMPK), a downstream component of a protein kinase cascade that acts as a sensor of cellular energy charge. (Winder WW et al., 1999) 


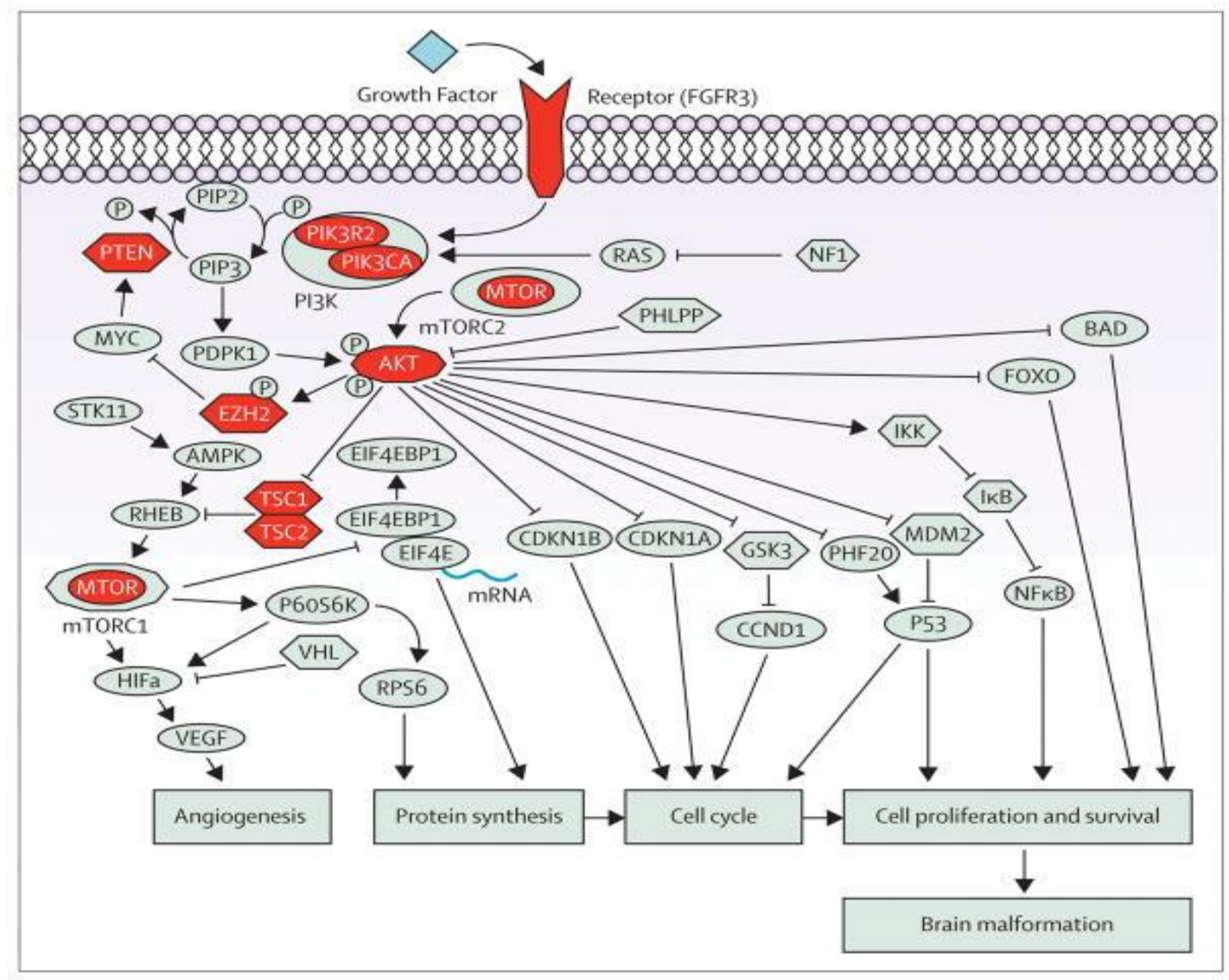

Figure 3: Schematic representation of the PI3K-AKT-mTOR signalling pathway. Genes encoding proteins with activator effects on the downstream signalling components are represented by ellipsis, genes encoding proteins with inhibitory effect are represented by hexagons and AKT gene family and mTORC1, which may have both activatory and repressor effect, are represented by decagons. Genes encoding proteins of the PI3K-AKT-mTOR pathway already implicated in malformations of cortical development in human disease are coloured in red. From (from Guerrini \& Dobyns 2014).

Activating the AMPK pathway, metformin eventually inhibits the mTOR pathway and causes a reduction in protein synthesis and cellular proliferation (Zhou G et al., 2001). Recently, Kim and collaborators demonstrated that early treatment with metformin prevented seizure onset and late treatment suppressed seizure frequency in FCD mice electroporated in utero with MTOR mutations identified in FCD patients (Kim et al., 2019.). With proven long-term safety and tolerability, metformin appears to be a promising alternative drug for the treatment of MCDs related to mTOR pathway dysregulation. 


\section{AIM OF THE STUDY}

MCDs are an important cause of epilepsy and intellectual disability. Because of the substantial genotypic and phenotypic heterogeneity observed in most MCDs, a detailed genetic analysis is necessary to clarify the molecular basis of these diseases. However, despite NGS technologies have considerably increased the potential of identifying the causal mutations in patients with MCD, in some cases NGS results have some limits of interpretation and functional studies are needed to clarify the role of some genetic variants. Although in most cases MCDs cannot be treated pharmacologically, recent evidences indicate that drugs able to regulate mTOR pathway activity may revert epileptic and malformation phenotype observed in animal models of FCD. The aim of this $\mathrm{PhD}$ project has been to apply a multidisciplinary approach to identify causative mutations in two patients with MCDs, validate the pathogenic role of selected identified mutations, and assess the effectiveness of novel treatments for mTOR pathway related MCDs. 


\section{MATERIALS AND METHODS}

\subsection{Patients}

In this $\mathrm{PhD}$ project, we studied a cohort of 102 patients who exhibited a wide spectrum of MCDs. In these patients, we performed gene panel analysis to provide molecular diagnosis. For two selected patients, we performed functional studies in vitro to explore the functional effects of the mutations identified and in one of them, carrying a mutation in the $m T O R$ gene, we assessed the effectiveness of metformin in reverting the aberrant phenotype induced by the causative mutation. For each patient participating to the study, we obtained an informed consent according to the directive of the Pediatric Ethic Committee of the Tuscany region.

\subsection{Samples}

We extracted Genomic DNA (gDNA) from whole blood and saliva using a QIA symphony SP automated robot (Qiagen, Hilden, Germany). We also extracted DNA from peripheral blood of patients' parents to test inheritance of those variants which were constitutive and to confirm absence of variants which were detected as somatic mosaicism. We quantified genomic DNA using a Quantus Fluorometer and the QuantiFluor ONE dsDNASystem (Promega, Madison, WI, USA).

For Patient 1, his parents, and three pools of eight healthy individuals each, we isolated lymphocytes for RTPCR and western blot analysis. (Lefort and Kim et al., 2017) For Patient 2, we collected fibroblasts from skin biopsies to assess metformin effectiveness in reverting mTOR pathway hyperactivation.

\subsection{Gene panel analysis}

We performed targeted resequencing of a panel including 105 genes (Table 2) known or predicted to be associated with MCDs using a custom-designed Nextera DNA Library Prep Kit and an Illumina MiSeq instrument (Illumina, SanDiego, CA) with a $2 \times 150$ bp paired end protocol as previously described (Parrini, et al., 2017). Variants were annotated and filtered using the ANNOVAR tool (Yang, H. et al., 2015). To confirm NGS results with an orthogonal method and perform the segregation analysis, we Sanger sequenced the variants in the patients, and then extended this analysis to their parents.

\begin{tabular}{llll}
\hline ACTB & EMX2 & LARGE1 & SHH \\
ACTG1 & ERMARD & MCPH1 & SIX3 \\
ADGRG1 & EXOSC3 & NDE1 & SLC25A19 \\
AMPD2 & EZH2 & NFIX & STIL \\
ARFGEF2 & FAT4 & NHEJ1 & TGIF1 \\
\hline
\end{tabular}




\begin{tabular}{llll}
\hline ARX & FIG4 & NSD1 & TMEM5 \\
ASNS & FKRP & OCLN & TSC1 \\
ASPM & FKTN & OPHN1 & TSC2 \\
ATRX & FLNA & PAFAH1B1 & TSEN15 \\
CASK & FOXC1 & PAX6 & TSEN2 \\
CCND2 & GLI2 & POMGNT1 & TSEN34 \\
CDK5 & GNAQ & POMT1 & TSEN54 \\
CDK5RAP2 & IER3IP1 & POMT2 & TUBA1A \\
CENPJ & ISPD & PQBP1 & TUBA8 \\
CEP135 & KATNB1 & QARS & TUBB \\
CEP152 & KIF1BP & RAB18 & TUBB2A \\
COL4A1 & KIF2A & RAB3GAP1 & TUBB2B \\
CUL4B & KIF5C & RAB3GAP2 & TUBB3 \\
DCHS1 & LAMA2 & RARS2 & TUBG1 \\
DCX & LAMB1 & RELN & VLDLR \\
DYNC1H1 & LAMC3 & RTTN & VRK1 \\
AKT1 & AKT3 & SEPSECS & WDR62 \\
CC2D1A & CCND2 & CNTNAP2 & DEPDC5 \\
EZH2 & GNAQ & MTOR & MYCN \\
NPRL2 & NPRL3 & PIK3CA & PIK3R2 \\
PTEN & STRADA & TBC1D7 & TSC1 \\
TSC2 & & & \\
\hline & & & \\
\hline
\end{tabular}

Table 2: MCDs associated genes analyzed by Nextera DNA Library Prep Kit (Illumina, San Diego, CA).

\subsection{Starvation protocol on skin fibroblast culture}

To test mTOR pathway hyperactivation in cells from Patient 2, we setup fibroblasts cultures starting from punch biopsies of the patient and a healthy control. To starve the cells, we substituted complete culture medium (Dulbecco's Modified - Eagle's Medium supplemented with 10\% Fetal Bovine Serum, 10 units/mL penicillin, and $10 \mathrm{mg} / \mathrm{mL}$ streptomycin, all from Life Technologies) with Hank's Balanced Salt Solution, (HBSS, Gibco) and maintained the cells in this medium for $8 \mathrm{~h}, 16 \mathrm{~h}$ or $24 \mathrm{~h}$.

\subsection{Western blot analysis}

We performed western blot analysis on lymphocyte cells isolated from peripheral blood of Patient 1, his parents and three pools of eight healthy individuals each; we electrophoresed $50 \mu \mathrm{g}$ of soluble cellular proteins through 4\%-12\% Bis-Tris precast polyacrylamide gels (Bio-Rad Laboratories) and then we blotted them onto a polyvinylidene difluoride (PVDF) membrane. We incubated the membrane with 1:4000 dilution of mouse monoclonal anti-LIS1 210 primary antibody (Sapir, Elbaum, \& Reiner, 1997) and then with 1:2000 dilution of goat anti-mouse secondary antibody (Thermo Fisher Scientific, MA). 
We also performed western blot analysis on cultured fibroblast of Patient 2 and of one control individual. We electrophoresed $10 \mu \mathrm{g}$ of soluble cellular proteins through precast 4-20\% MP TGX Stain-Free Gels (Bio-Rad Laboratories) and then we blotted them onto a polyvinylidene difluoride (PVDF) membrane. We incubated the membrane with 1:1000 dilution of Rabbit Phospho-S6 Ribosomal Protein antibody (Ser240/244) (D68F8, Cell Signaling Technologies) and with 0.4:1000 dilution of Actin antibody produced in rabbit (A2066, Sigma-Aldrich). Then, we incubated the membranes with 1:5000 dilution of Goat Anti-Rabbit IgG H\&L (AB6721, Abcam).

We performed the visualization of antibodies binding by enhanced chemiluminescence (ClarityTM Western ECL Substrate, Bio-Rad Laboratories), according to the manufacturer's recommendations on a ChemiDoc ${ }^{\mathrm{TM}}$ Imaging System (Bio-Rad Laboratories).

\subsection{Reverse transcriptase - PCR analysis and quantitative Real - Time PCR analysis (qPCR)}

We performed RT-PCR analysis on total RNA isolated from blood lymphocytes of Patient 1 and his parents using the PAXgene BloodRNA Kit (Qiagen, Hilden, Germany). We synthetize cDNA with random hexamers and the Expand Reverse Transcriptase kit (Roche, Carlsbad,CA) using 500 ng of total RNA as template. We Sanger sequenced the RT-PCR products on both strands using the BigDye Terminator v1.1 chemistry (Applied Biosystems, CA) and the 3500 DX Genetic Analyser (ThermoFisher Scientific, MA) (Table 3). We performed qPCR gene expression analysis on cDNA of using a PAFAH1B1 TaqMan probe (Hs00928513_g1, Thermo Fisher Scientific). We calculated statistical significance using Student's t tests $(\alpha$ $=0.05)$.

\begin{tabular}{|c|c|}
\hline Primers RT-PCR & Sequence $5^{\prime} \longrightarrow 3^{\prime}$ \\
\hline PAFAH1B1_F (exons 3_4) & TGAATTAGATGTGAATGAAG \\
\hline PAFAH1B1_R(exons 9_10) & TGACCCACGAGGGTCATAA \\
\hline PAFAH1B1_F (exons 4_5) & ACAAAAGAAGGTTATGGAA \\
\hline PAFAH1B1 R(exons 8 9) & TTTTTAGTCTCAGATCCT \\
\hline
\end{tabular}

Table 3: Primer sequences used to test LIS1 exon splicing by RT-PCR.

\subsection{Immunofluorescence}

To validate results of WB analysis in fibroblasts of Patients 2, we determined P-RS6 expression level by immunofluorescence microscopy. We used a Burker chamber to count 50.000 fibroblasts from the patient and the control and cultured them over night into multiwells containing coverslips. We fixed cells for 12 minutes in ice-cold $4 \%$ paraformaldehyde, rinsed with PBS, and incubated the samples for 10 min with PBS 
containing Triton $0.075 \mathrm{X}$ to improve antibody penetration. After rinsing in PBS, we blocked in $2 \%$ BSA and then incubated the samples with Rabbit Phospho-S6 Ribosomal (Ser240/244) (D68F8, Cell Signaling Technologies) primary antibody (1:2000) for $1 \mathrm{~h}$ at room temperature (RT).After rinsing in PBS, we incubated the samples with Goat-Anti-Rabbit IgG - FITC secondary antibody (F9887, Sigma 1: 2000). Then, we stored cells at $4^{\circ} \mathrm{C}$ in the dark until microscopic analyses. We captured fluorescent cells images using an EUROStar III Plus (Euroimmun) microscope, performing the acquisitions in 10X field, with FiJi (https://imagej.net/Fiji) software.

\subsection{Drug treatments}

We treated cultured fibroblasts of Patient 2 and one control with Everolimus (Abcam, 100nM, 24h treatment) and Metformin at three different concentrations (Metformin hydrochloride, Abcam, 5Mm, 10mM, 15Mm, $24 \mathrm{~h}$ treatment). For both cultures, we used DMSO as vehicle control.

\subsection{MTT assay}

We seeded fibroblasts of Patient 2 and a control individual, cultured with drugs as previously described, at a density of $3.1 \times 10^{4}$ cells $/ \mathrm{cm}^{2}$ into 96-multiwells culture plates and assessed cell viability using the 3-(4,5dimethylthiazol-2-yl)-2,5-diphenyltetrazolium bromide (MTT) assay. We added $5 \mu \mathrm{L}$ of MTT solution (1 $\mathrm{mM}$ in PBS), diluited in DMEM medium, to each well. After incubation for $2 \mathrm{~h}$ at $37^{\circ} \mathrm{C}$, we dissolved the purple-blue MTT formazan precipitate in $100 \mu \mathrm{L}$ of DMSO and measured the absorbance with the multiplate reader SpectraMax M2 (Crisel Instruments) at $560 \mathrm{~nm}$. 


\section{RESULTS}

Using NGS panel analysis, we identified causative mutations in known MCD genes in 18 out of 102 screened patients (17.6\%). Using in vitro analysis, we elucidated the functional effect of two mutations (one in LISI and the other in mTOR) identified in two unrelated patients and demonstrated that fibroblasts of patients carrying mutations in $m T O R$ pathway genes can be successfully used to perform preliminary screening of drug effectiveness. We also demonstrated that metformin is effective in reverting the aberrant phenotype induced by p.Thr1977Ile mTOR mutation.

\subsection{Clinical findings and gene panel analysis:}

Patient 1: The patient is a 7-year-old boy who was born at term from unrelated parents. Epilepsy onset occurred at age 2 years, with focal motor seizures during sleep and recurrent nocturnal paroxysmal confusional arousals. At age 5 years, clusters of diurnal seizures also appeared, consisting of visual illusions, and ictal fear with secondary generalization. Background EEG showed unusual fast rhythms and multifocal spikes. Intellectual disability became more apparent in childhood causing the child to enter primary school 1 year later with special needs. Language was delayed with greater involvement of expressive skills. Motor coordination was clumsy. Brain MRI revealed pachygyria with clearcut posterior greater than anterior severity gradient, with more obvious, yet mild, cortical thickening and simplified cortical pattern in the parieto-occipital regions (Figure $4, \mathrm{f}-\mathrm{j}$ ).

The boy's mother manifested, since the age of 4 years, focal seizures, confusional paroxysmal arousals and infrequent episodes of ictal fear and visual illusions. An isolated tonic-clonic seizure occurred at the age of 7 years. Her EEG was similar to that of her son. Although this woman's early development was deemed as normal and expressive language delay was not reported in infancy, she had been on special needs since primary school due to learning difficulties. Her first and only brain MRI, performed at the age of 37 years (OFC $53 \mathrm{~cm}:$ 11th percentile), showed increased cortical thickness and a simplified cortical pattern in the parieto-occipital regions (Figure 4, a-e).

Genes panel analysis identified a nucleotide variant in exon 7 of the LISI gene (Genbank Accession: NM_000430.3), c.655 T > A, resulting in the [p.(Trp219Arg)] missense substitution. This variant was not reported in public available databases such as the Exome Aggregation Consortium (ExAC), the Genome Aggregation Database (gnomAD) and the 1000 Genomes Project database. The variant segregated in the proband's mother but not in his healthy maternal aunt. Maternal grandparents were not available for segregation analysis. 


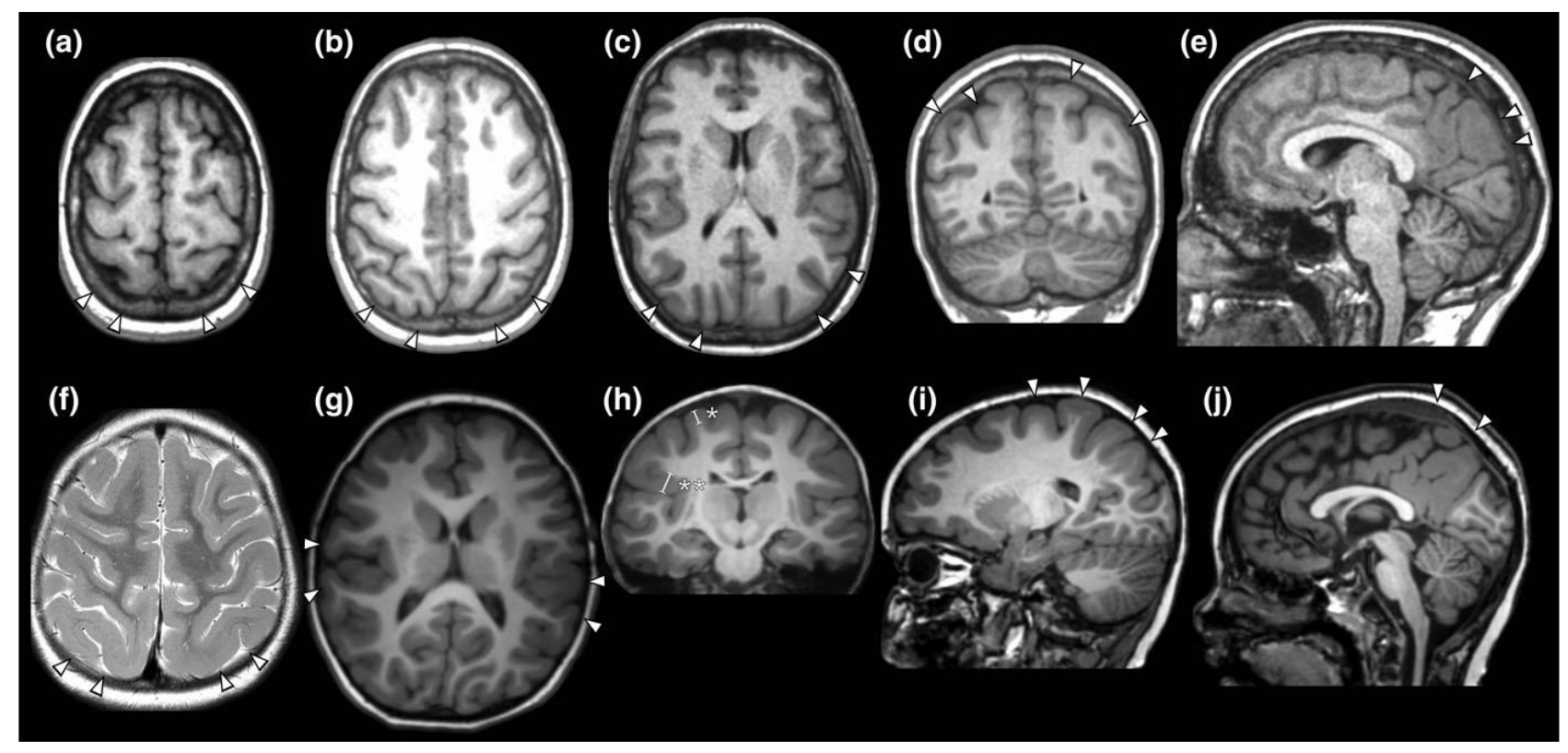

Figure 4: Brain MRI scans performed in the Patient's 1 mother $(\mathrm{a}-\mathrm{e})$ and in the Patient $1(\mathrm{f}-\mathrm{j})$. Plots a-e and $\mathrm{g}-\mathrm{j}$, are all T1 weighted; plot $f$ is T2weighted. Top row (mother): Axial sections $(a-c)$ show cortical thickening with mild simplification of the gyral pattern in the parieto-occipital brain regions (arrowheads). The coronal section (d) and the sagittal section (e) show how thickening and simplification in the posterior cortex involved both the lateral and mesial aspects (arrowheads). Lower row (Patient 1): Axial sections $\mathrm{f}$ and $\mathrm{g}$ show cortical thickening with mild simplification of the gyral pattern in the posterior brain regions (f) and in the insular cortex, with pronounced infolding ( $g$ ) (arrowheads). The coronal section $h$ and the sagittal sections $i$ and $j$ show how thickening and simplification in the posterior cortex involve both the lateral and the mesial aspects (arrowheads). Plots f, and especially $i$ and $j$ also show that a milder degree of gyral simplification is also present in the frontal lobes with a clear-cut gradient of progressive anterior-posterior thickening fully appreciable in i. Cortical thickness, as measured in $h$ (white bars across the cortex)varies from 6 to $9 \mathrm{~mm}$ (thickness of the normal cortex is around $4 \mathrm{~mm}$ ). No abnormalities of the corpus callosum, cerebellum, and brainstem were present in these two patients (from De Vita et al., 2018).

Patient 2: The patient is a 10-year-old boy who was born at term from unrelated parents after normal pregnancy and delivery. He showed profound intellectual disability, hypotonic quadriparesis, megalencephaly (+2.5 SD), macrosomia, linear streaks of hypo- and hyper-pigmented skin following the lines of Blaschko (skin color pattern consistent with cutis tricolor of the Blaschko-linear type, which consists of diffuse alternating hypopigmented and hyperpigmented streaks), diffuse retinal depigmentation, bilateral cryptorchidism, facial dysmorphisms (prominent frontal bossing, high forehead, large, hypoplastic nasal root, anteverted nostrils, low set ears with folded helix, pronounced philtrum, short neck), bilateral frontalparietal-insular polymicrogyria and focal epilepsy. (Figure 5).

Genes panel analysis identified a single nucleotide variant in exon 43 of the MTOR gene (Genbank Accession: NM_004958.3), c.5930 C>T, resulting in the [p.(Thr1977Ile)] substitution. The mutation was present as somatic mosaicism (20\%) in blood. NGS analysis on different tissues revealed different percentages of mosaicism in saliva (10\%) and fibroblast isolated from the hyperpigmented (55\%) and hypopigmented (42\%) streaks. This variant was not reported in public databases such as the Exome 
Aggregation Consortium (ExAC), the Genome Aggregation Database (gnomAD) and the 1000 Genomes Project database. Segregation analysis showed that, as expected, the variant was absent in paternal and maternal DNA.
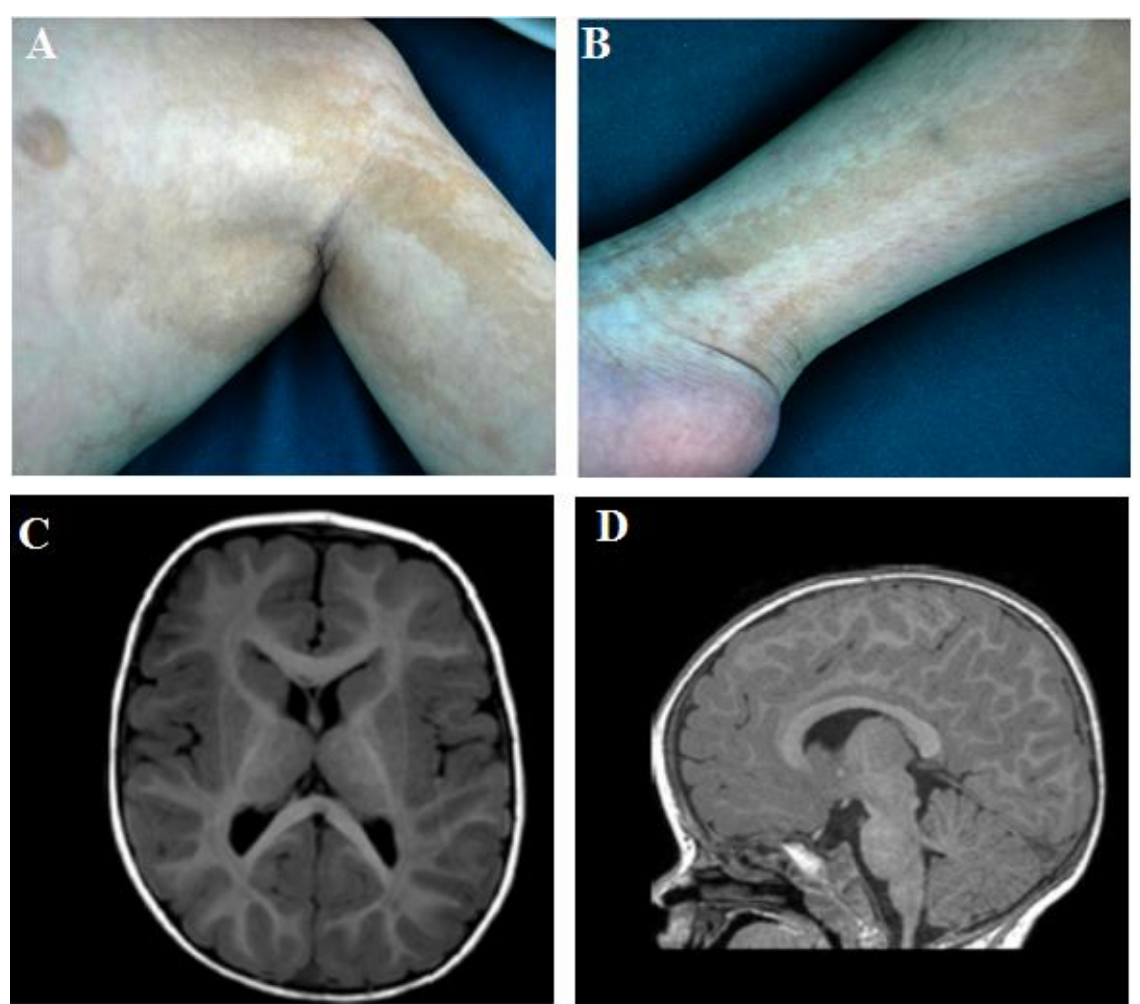

Figure 5: (A, B) Patient 2 images showing linear streaks of hyperpigmented and hypopigmented skin corresponding to cutis tricolor of the Blaschko-linear type. (C, D): T1 weighted axial MRI scans of Patient 2 showing bilateral frontal-parietal-insular polymicrogyria. 


\subsection{Functional validations of identified mutations on patients' samples:}

\section{Patient 1:}

In Patient 1, we used the western blot method to determine the amount of the LIS1 protein. This analysis detected the expected LIS1 band at $45 \mathrm{kDa}$ in all samples and showed equal protein levels in lymphocyte cells of affected individuals (proband and his mother) compared to his father and control pools (Figure 6).

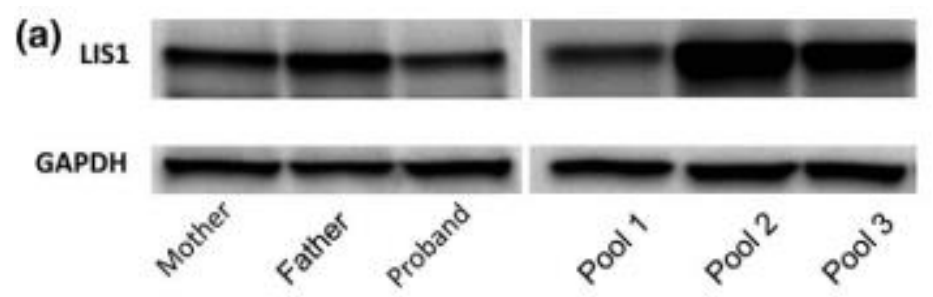

(b)

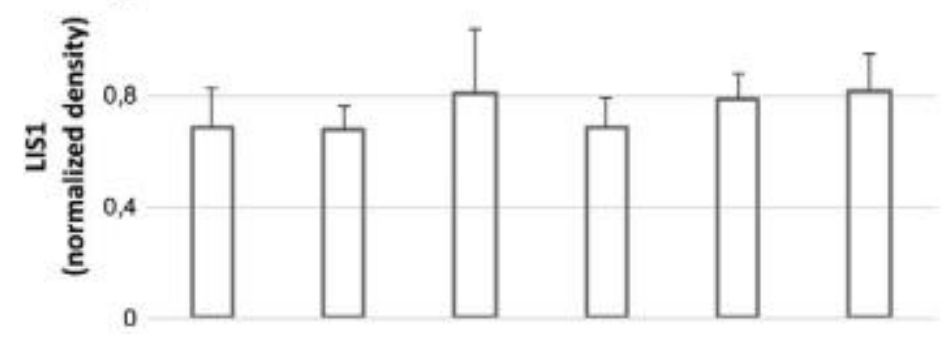

Figure 6: (a) Western blot analysis with anti-LIS1 antibody on lymphocyte lysates of the proband, his parents and three pools (pool 1 to 3) obtained from eight unrelated individuals each. The same filters were also probed with anti-GAPDH antibody for cell lysate normalization. (b) LIS1 normalized values, obtained by chemiluminescence detection, are reported in the chart as mean values \pm SD relative to CTRLs of three-independent experiments. There are not significant differences between individuals carrying the LIS1 mutation and the controls $(\mathrm{p}>0.05)$ (De Vita et al.,2018)

To exclude an aberrant splicing, we used RT-PCR to amplify a 906 base pairs cDNA fragment including exons 3-4 and 8-9 junctions of LISI gene. This analysis showed no aberrant mRNA and a similar amount of the wild-type and mutant allele. qPCR gene expression analysis showed that the LIS1 gene was similarly expressed in both the proband and his parents. (figure 7) 

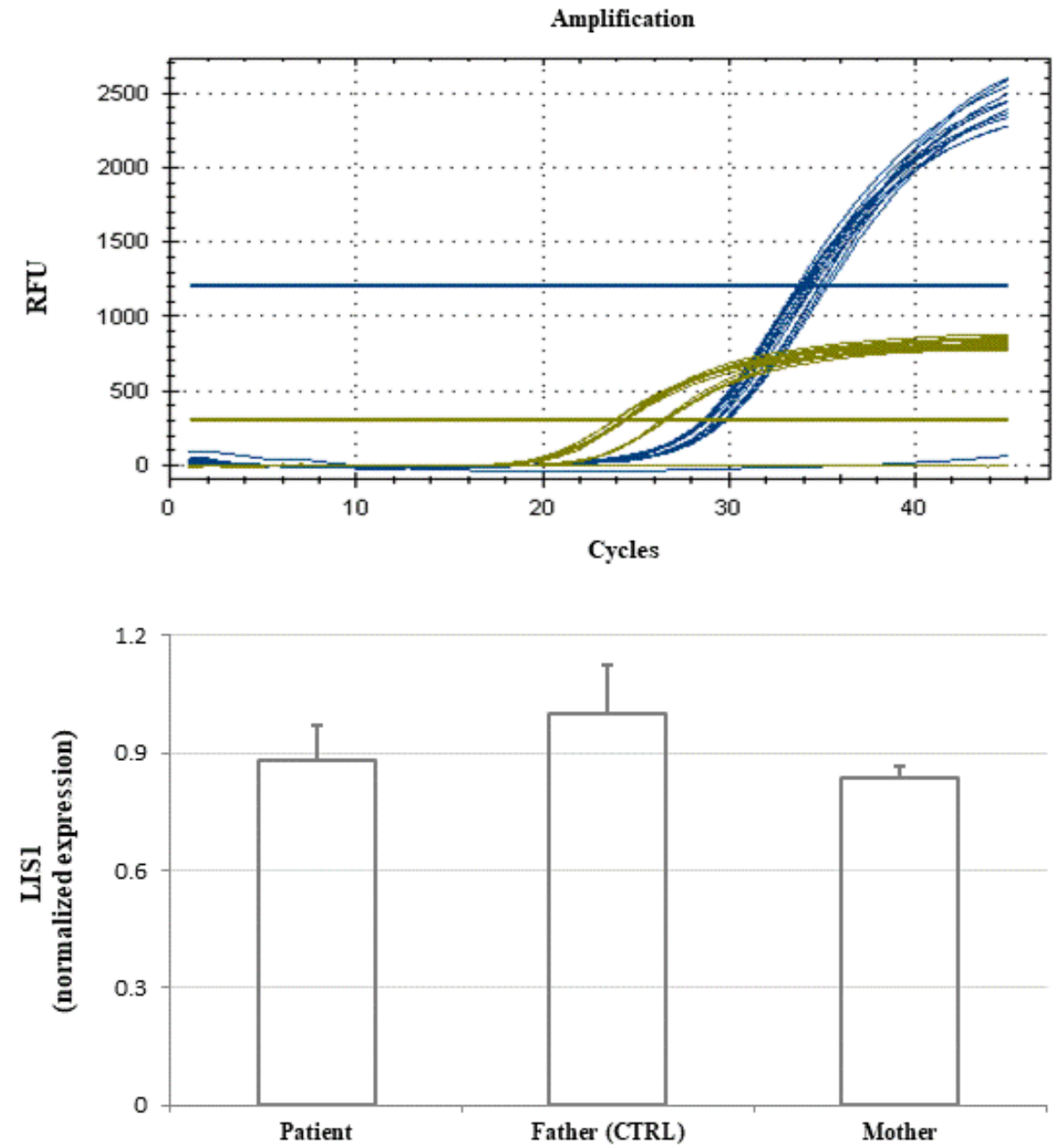

Figure 7: LIS1 TaqMan real time PCR amplification for 10ng of diluted cDNA of Patient 1 and his parents that show LIS1 gene similarly expressed in all samples. 


\section{Patient 2:}

In Patient 2, we used the western blot method to confirm that the p.Thr1977Ile mTOR mutation induced hyperactivation of the mTOR pathway in fibroblasts in starving conditions. In wild type cells, starving conditions determine mTOR pathway inactivation and cells quiescence. At T0 (complete medium) the expression of P-RPS6 in patient's cells was higher than that observed in control's cells (figure 8). Upon starving patient's and control's cells, we observed a statistically significant reduction of P-RPS6 after 16h or 24h of HBSS incubation in both in control and patient fibroblasts. (figure 8).

(a)

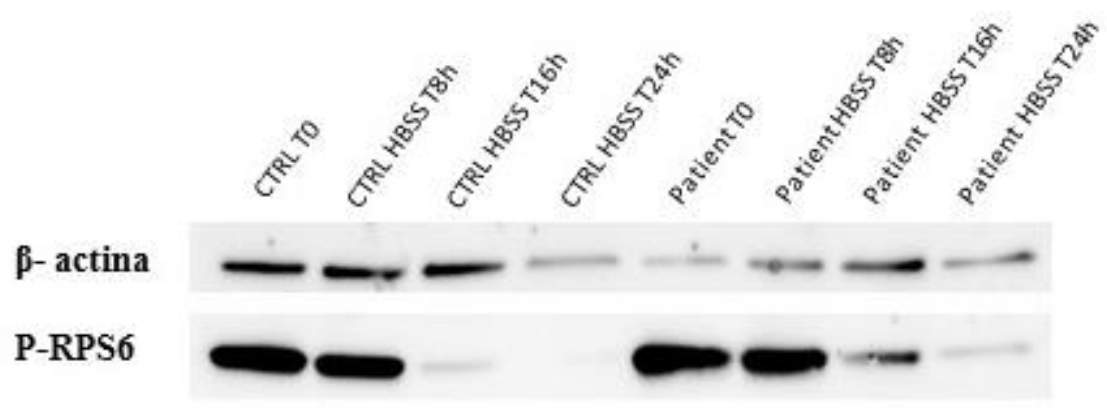

(b)

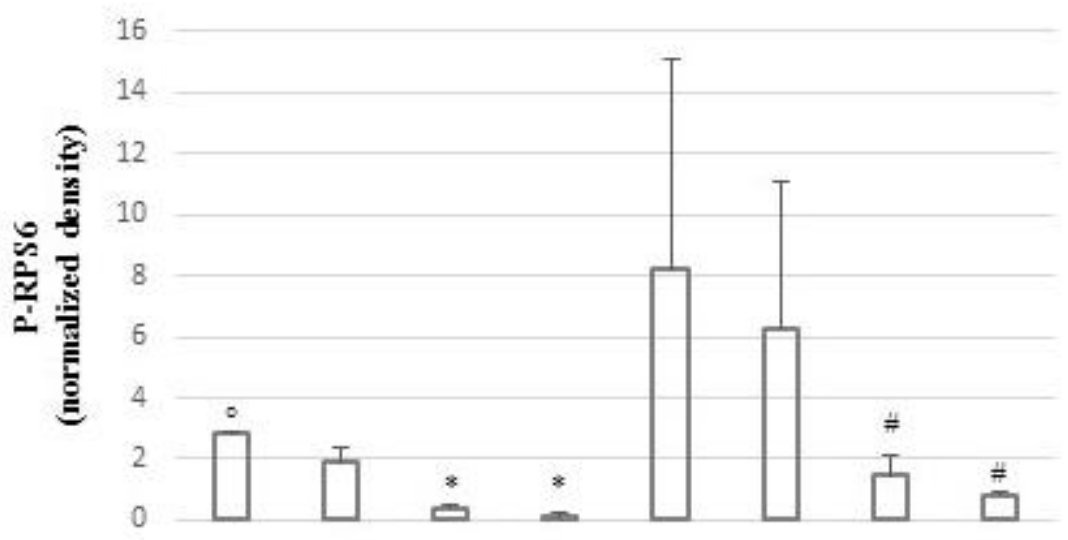

Figure 8: (a) Western blot analysis with anti P-RPS6 on fibroblast lysates of the patient and a control individual. The same membranes were also probed with anti $\beta$-actina antibody for cell lysate normalization. (b) P-RPS6 normalized values, obtained by chemiluminescence detection are reported in the chart as mean values \pm SD of three-independent experiments. Expression of PRPS6, at T0, was lower in control's cells than in patient's cells $\left({ }^{\circ} \mathrm{p}<0.05\right) .16 \mathrm{~h}$ and $24 \mathrm{~h}$ incubation in HBSS determined statistically significant reduction of P-RPS6 expression in both patients' and control's cells (*,\# p < 0.05).

Although we observed a significant reduction in P-RPS6 expression levels both in control's and patient's fibroblasts after 16 and 24 hours of incubation in HBSS, P-RPS6 expression levels in the patient's fibroblasts remained significantly higher than those observed in control's fibroblasts (Figure 9). Although in both samples HBSS treatment determined a statistically significant reduction of P-RPS6 (Figure 9), its expression remained significantly higher in patient's fibroblasts with respect to control fibroblasts, confirming the hyperactivating effect of the p.Thr1977Ile mTOR mutation. 


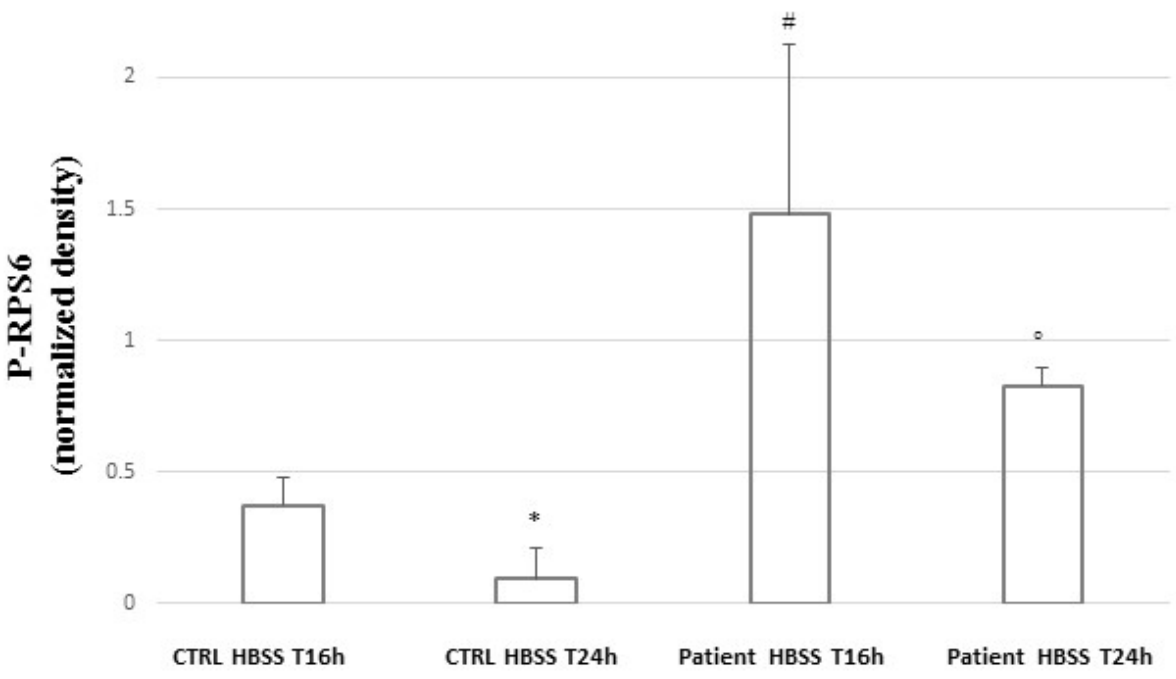

FIGURE 9: Expression of P-RPS6 in patient's and control's fibroblasts after 16h and 24h of starvation. Expression of P-RPS6 was higher in patient's cells than control's cells at both T16h $(\# \mathrm{p}<0.05)$ and T24h $\left({ }^{\circ} \mathrm{p}<0.05\right)$. P-RPS6 expression reduction between T16h and T24h was statistically significant in control's cells $(* \mathrm{p}<0.05)$ but not in patient's cells.

Immunofluorescence assays performed upon starving both patient's and control's cell cultures for 16h with HBSS confirmed the results obtained via western blot (Figure 10).

(1)

CONTROL

\section{PATIENT}

DMEM
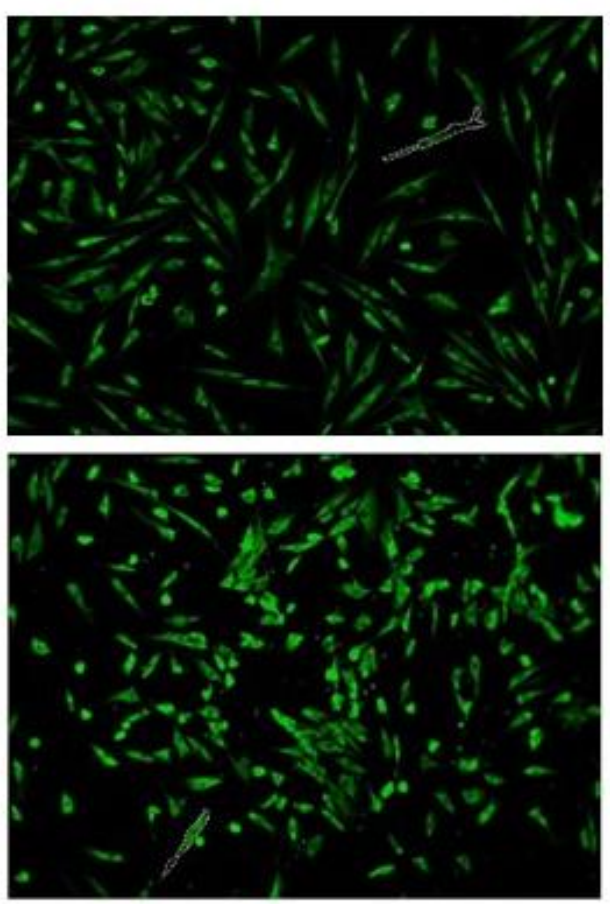

HBSS
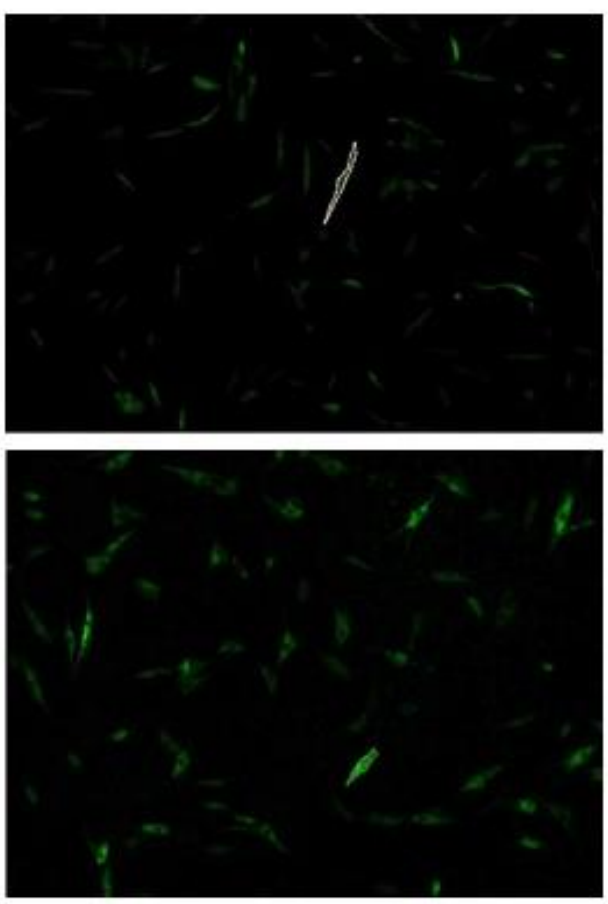
(a)

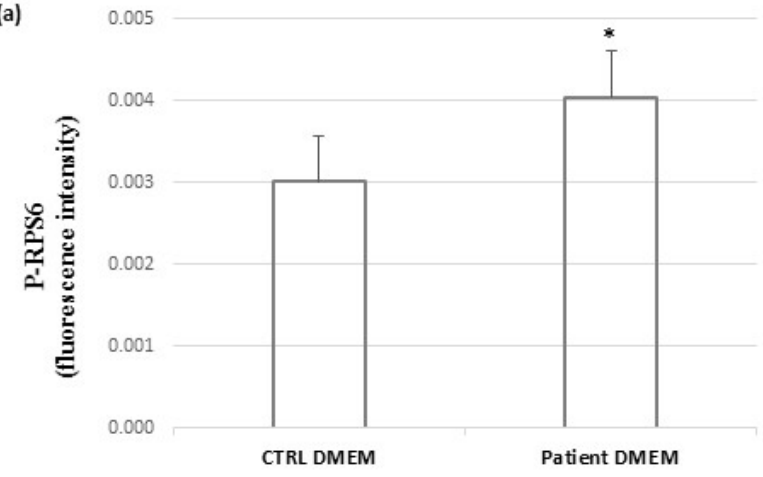

(c)

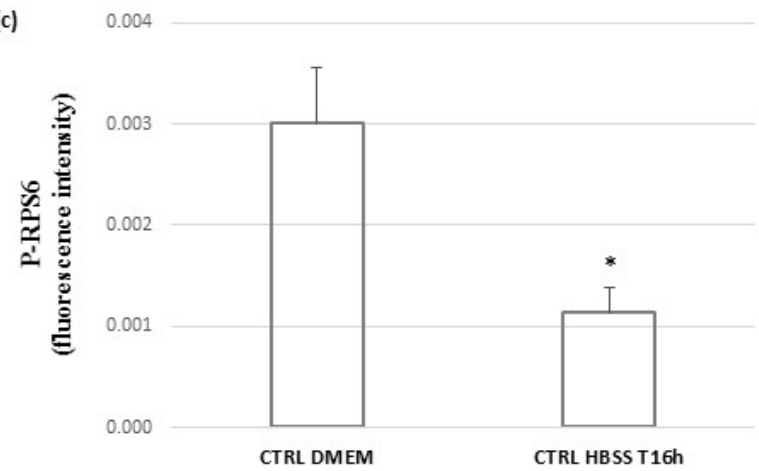

(b)

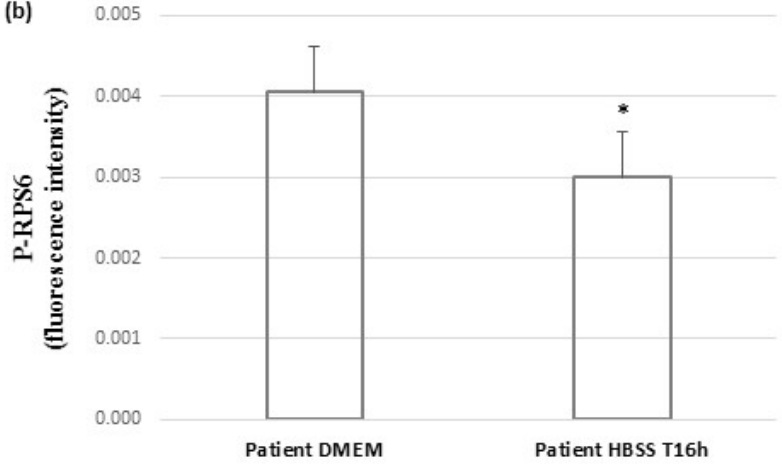

(d)

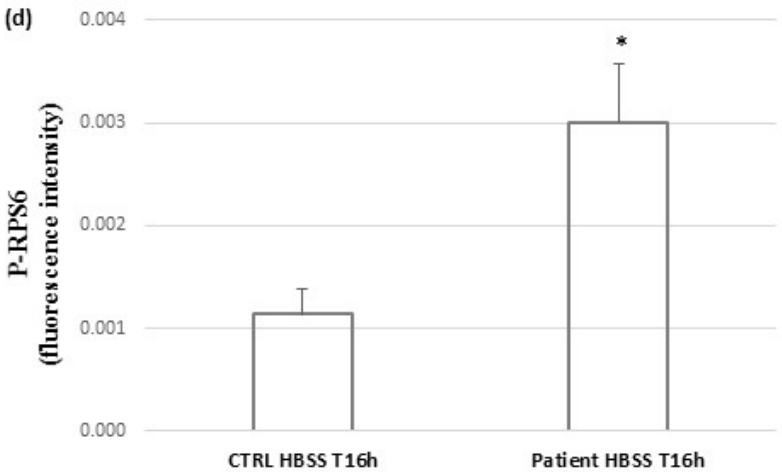

Figure 10: (1) Immunofluorescence images (10X field) with anti P-RPS6 antibody on fibroblasts of a control individual and patient 1 after culture in the DMEM medium and HBSS. Captured fluorescence images were analyzed by FiJi (https://imagej.net/Fiji) software. (2) Plots representing the normalized values of P-RPS6 protein amount detected by immunofluorescence. P-RPS6 values are significantly higher in patient's cells than control's cells (a). Although both in patient's cells (b) and control's cells (c) incubation in HBSS for $16 \mathrm{~h}$ results in a reduced expression of the protein, P-RPS6 expression remains significantly higher in patient's cells than in control cells $(\mathrm{d})(*=\mathrm{p}<0.05)$.

Once proven that p.Thr1977Ile mTOR mutation hyperactivate mTOR pathway, we aimed at rescuing the phenotype induced by the mutation treating both patient's and control's cell cultures with metformin, using Everolimus as a positive control of mTOR pathway inactivation and assessing the effectiveness of the treatment by western blot (Figure 11, a-b) . We found that metformin 5mM was sufficient to reduce P-RPS6 expression in both control and mutant cells. The level of expression of P-RPS6 after treatment with metformin $5 \mathrm{mM}$ was comparable to that observed in untreated control cells. (figure 12). Metformin $15 \mathrm{mM}$ caused a reduced expression of $\beta$-actin in control cells, suggesting a cytotoxic effect that was confirmed by MTT assay (Figure 11, c). Interestingly, this reduction was not present in mutant cells, confirming that p.Thr1977Ile mTOR mutation influences cells viability. 
(a)
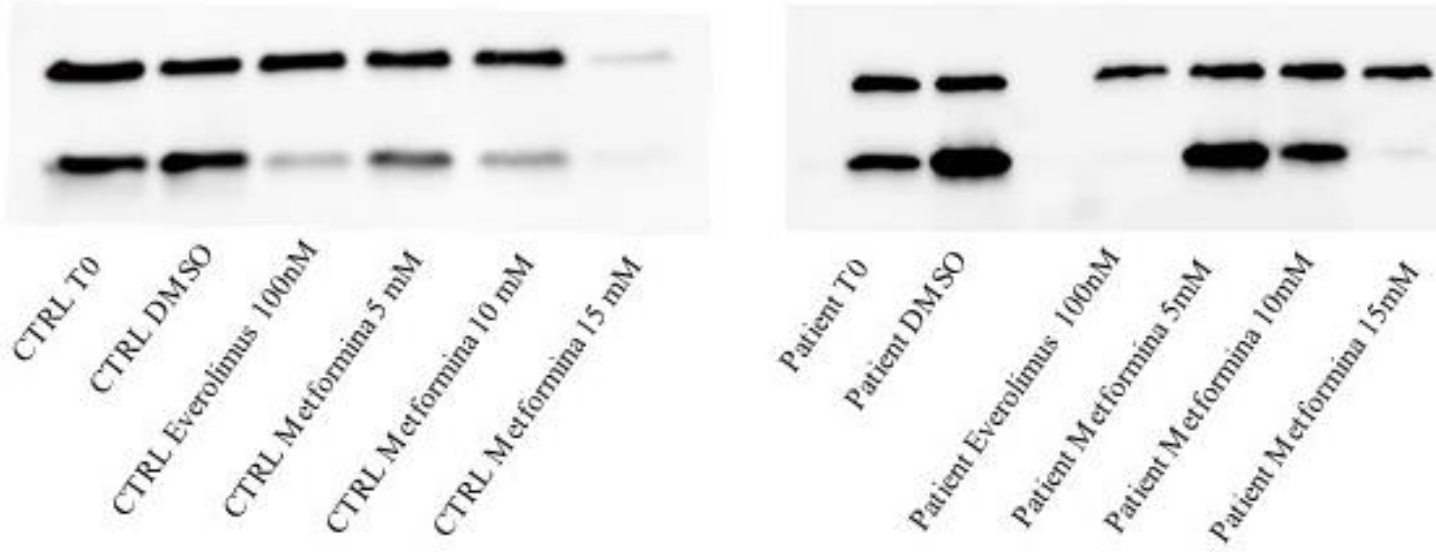

(b) 12
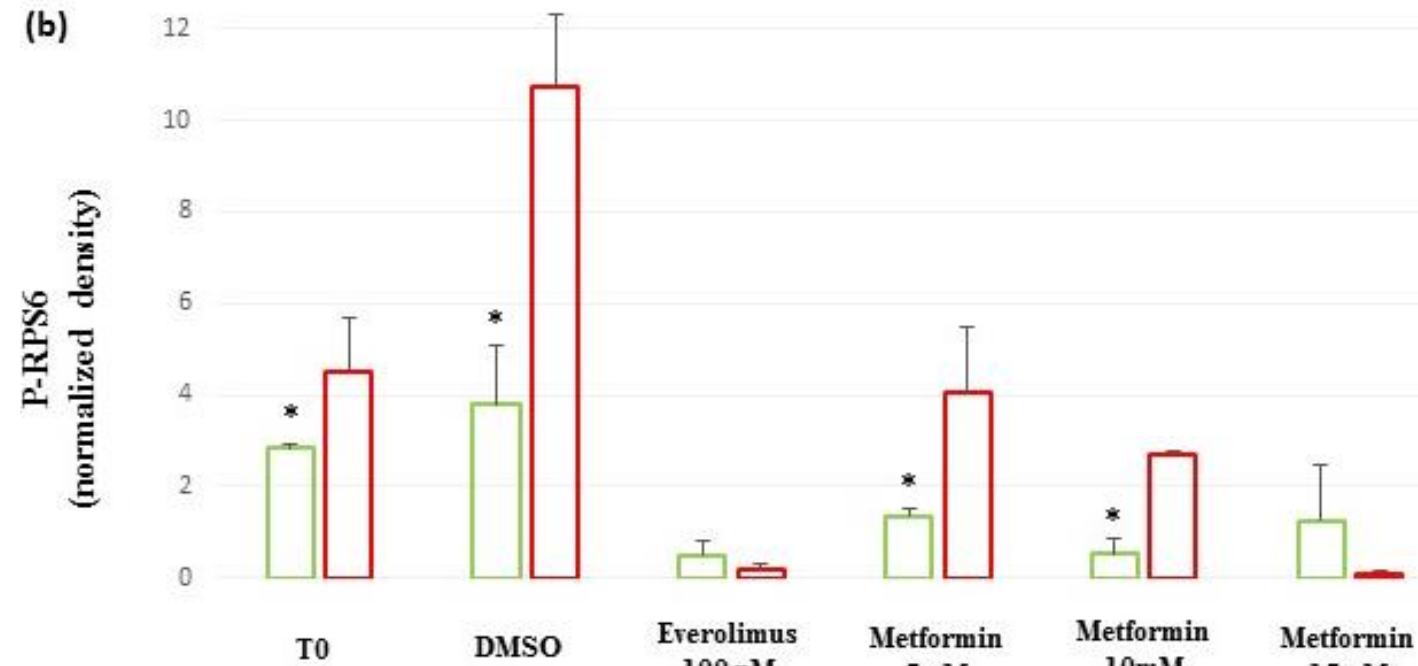

T0

Ererolimus

Metformin
$5 \mathrm{mM}$

Metformin

Metformin
$15 \mathrm{mM}$
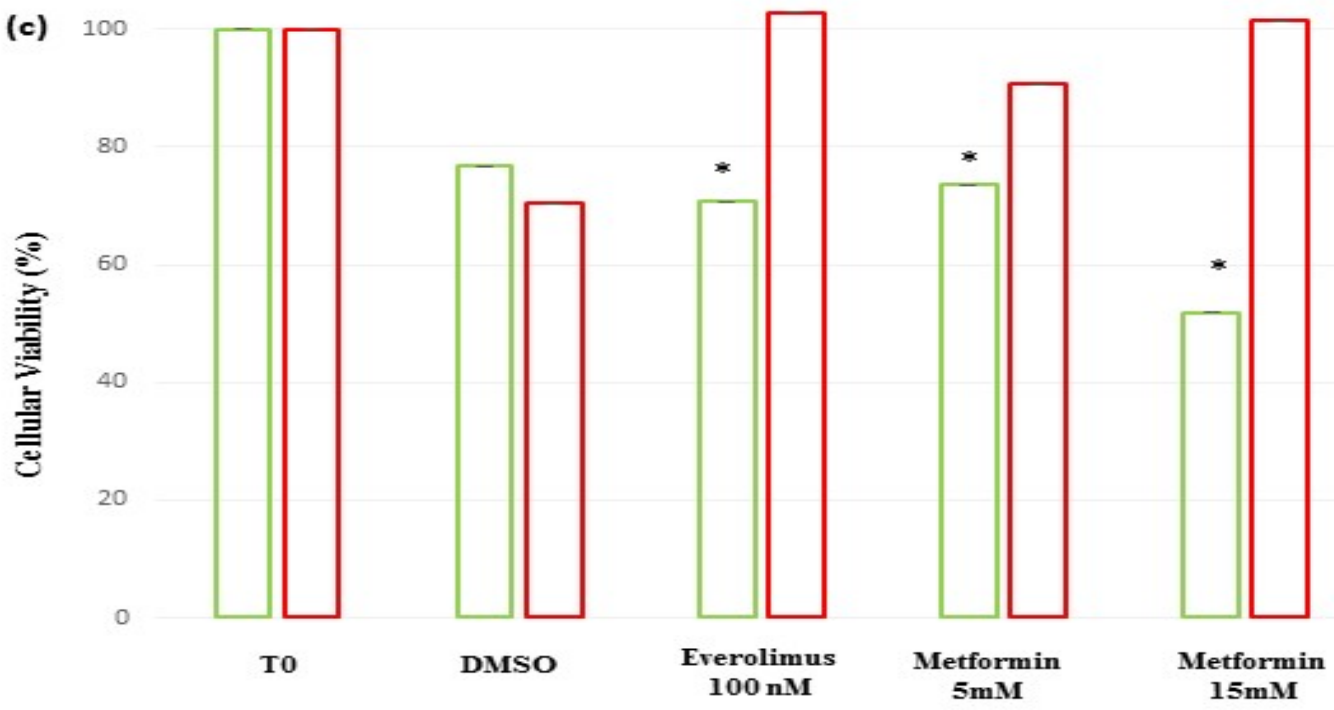
Figure 11: (a) Western blot analysis with anti P-RPS6 on fibroblast lysates of the patient and a control individual. The same membranes were also probed with anti $\beta$-actina antibody for cell lysate normalization. Fibroblast cells of control and patient were treated for $24 \mathrm{~h}$ with $100 \mathrm{nM}$ of Everolimus and with $5 \mathrm{mM}, 10 \mathrm{mM}$ and $15 \mathrm{mM}$ of Metformin. (b) P-RPS6 normalized values, obtained by chemiluminescence detection are reported in the chart as mean values $\pm \mathrm{SD}$ of three-independent experiments. Expression of PRPS6, at T0, DMSO, Metformin 5mM and 10mM, was lower in control's cells than in patient's cells (* p < 0.05). (c) Cells viability of control's and patient's cells, after drugs treatments, was assessed using MTT assay. Viability of control's cells, after drugs treatments are significantly lower then patient's cells viability. Data are normalized to T0 and are expressed as mean \pm S.D of threeindependent experiments. $(* \mathrm{p}<0.05)$

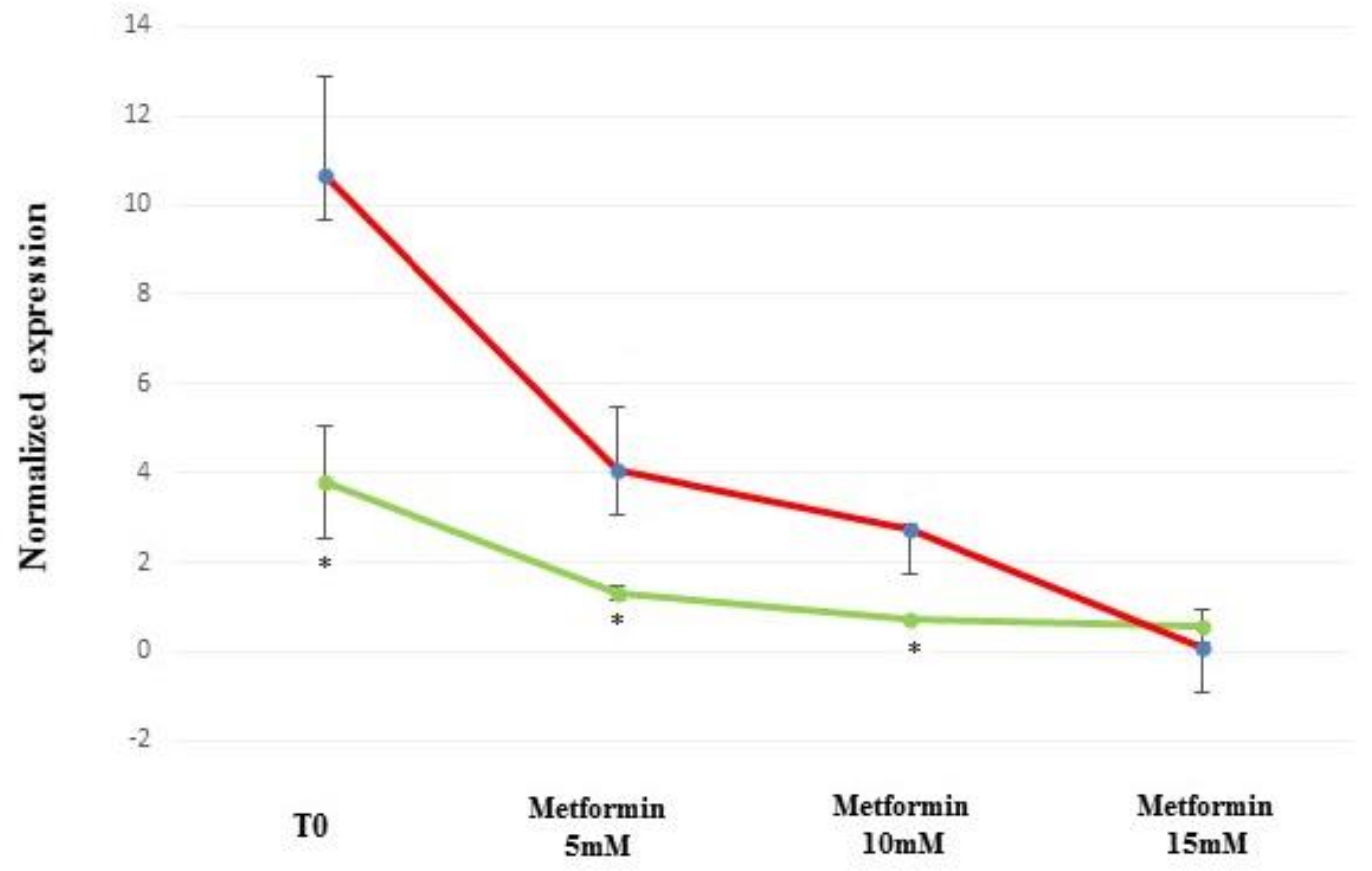

Figure 12: Effects of different concentration of Metformin on the expression of P-RPS6 in control's fibroblast cells and patient's fibroblast cells. At the concentration of $5 \mathrm{mM}$, the profile expression of the protein in patient is comparable with that in the control individual $(*=\mathrm{p}<0.05)$. 


\section{Discussion}

In this $\mathrm{PhD}$ project, we applied a multidisciplinary approach to identify causative mutations in patients with MCDs, characterize functional effects of two selected mutations and assess the effectiveness of a novel potential pharmacological treatment in one of them.

The first mutation (Trp219Arg missense mutation in the LIS1 gene) was identified in a male patient with delay of expressive language, intellectual and motor developments and pachygyria. The patient inherited the mutation from his affected mother. The p.Trp219Arg substitution is novel and causes a non-conservative change in a highly conserved residue replacing a non-polar-charged amino acid (Trp) with a polar-charged one (Arg) (Figure 13).
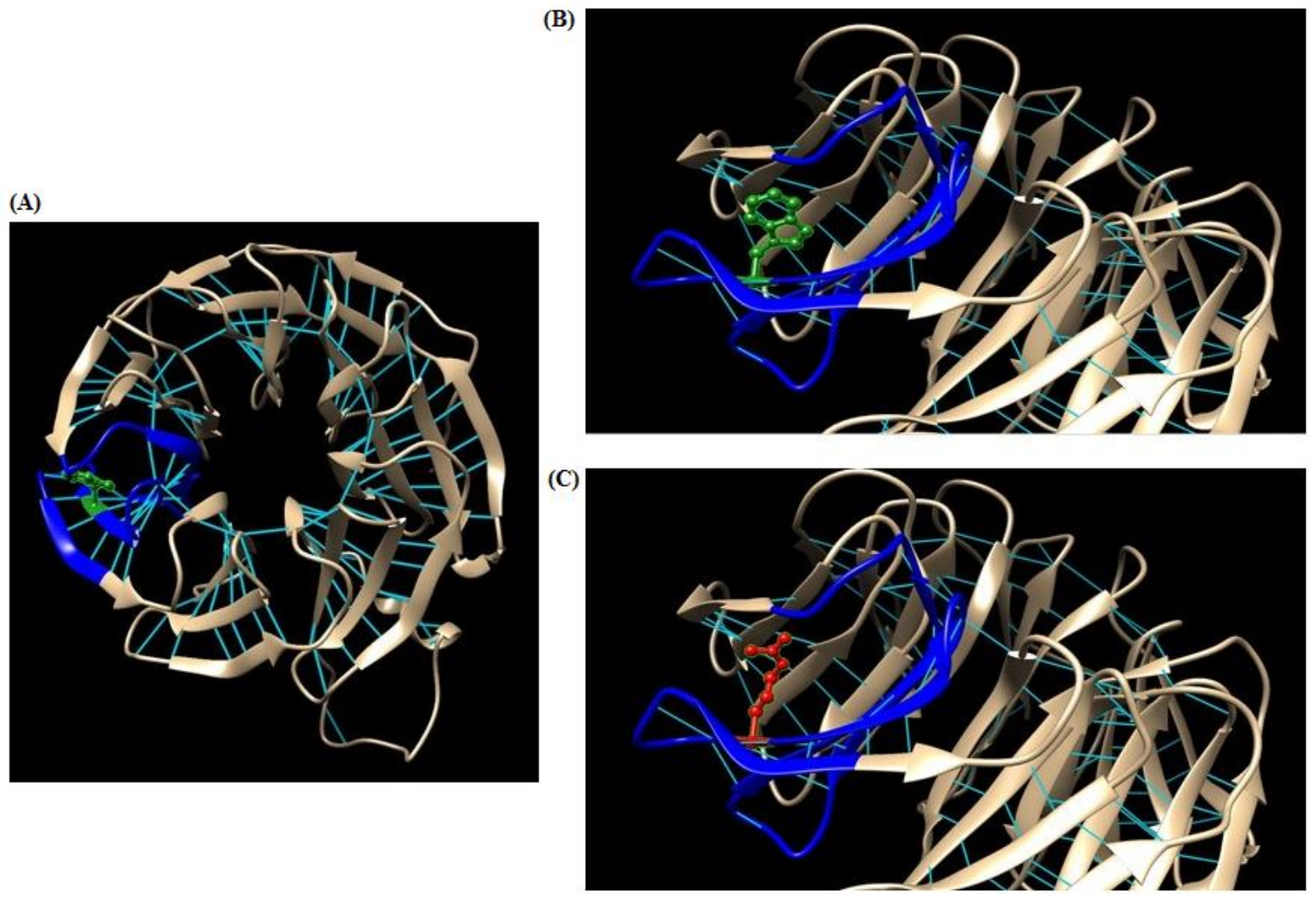

Figure 13: (A) LIS1 protein structure modeled by SwissModel (https://swissmodel.expasy.org/).and analyzed with Chimera (https://www.cgl.ucsf.edu/chimera/).Blue color highlighted the third WD40 repeat of LIS1, where the Trp219 wild-type residue is located. The substitution we found in Patient 1 causes a non-conservative change in a highly conserved residue, replacing a nonpolar-charged aminoacid (Trp, B) with a polar-charged one (Arg, C).

The Trp219 residue is located in the third WD40 repeat of LIS1 gene, which is important for the dimerization and the interaction of the protein with the PAF-AH catalytic subunits $\alpha 1$ and $\alpha 2$ (Saillour et al.,2009). Although, it was initially suggested that LIS1 missense mutations may result in a less severe phenotype (Leventer et al., 2001), the increased number of reports have shown that the phenotypic spectrum actually 
spans from normal IQ to severe intellectual disability, and from mild MRI findings, such as posterior subcortical band heterotopia, to severe lissencephaly (Leventer et al., 2001; Saillour et al.,2009). This is a proof of the extreme phenotypic variability associated with LIS1 missense mutations. Caspi et al. (2003) demonstrated that missense substitutions have variable impacts on the protein in terms of folding, proteinprotein interactions, and stability and are linked to an equally variable phenotypic severity. For this reason, to explore if the mutation we observed impaired one of these processes, we performed a LIS1 gene expression study by qPCR, which detected no significant differences between proband, mother and controls and Western Blot, which detected normal levels of the LIS1 protein in the proband and in his mother compared to controls. Therefore, the p.Trp219Arg mutation alters neither qualitative nor quantitative LIS1 expression and does not appear to cause defective folding and degradation of the mutant protein. These results suggest that the p.Trp219Arg mutation might instead cause mildly defective protein-protein interactions, resulting in a mild phenotype. They also suggest that different extents of impairment of this mechanism might contribute to the considerable phenotypic variability observed among individuals with LIS1 missense variants.

We published these results during the second year of $\mathrm{PhD}$ (De Vita et al. 2018, Familial dominant epilepsy and mild pachygyria associated with a constitutional LIS1 mutation. Am J Med Genet A. 2018 Dec;176(12):2808-2812.) and this is the first report of a constitutional LIS1 mutation inherited from an affected parent: the relatively mild clinical and imaging features observed in these individuals, especially in the mother, with respect to the usually severe LIS1-associated phenotypes, suggest that inheritability is possible if the phenotype is not severe enough to cause reproductive disadvantage and parents of patients harboring LIS1 mutations, especially if associated with mild phenotypes, should be assessed for their mutation carrier status.

The second mutation, p.Thr1977Ile mosaic missense mutation in the mTOR gene, was identified in a male patient who presented profound intellectual disability, megalencephaly $(+2.5 \mathrm{SD})$, cutaneous pigmentary mosaicism, bilateral frontal-parietal-insular polymicrogyria, and focal epilepsy. The p.Thr1977Ile mutation causes the replacing of a polar-charged amino acid (Thr) with a non-polar-charged one (Ile) (Figure14), and is located in the FAT domain that structurally gives access to the mTOR kinase. Interestingly, most MTOR pathogenic variants are located in this domain. (Marsan et al. 2018). The p.Thr1977Ile mTOR variant is recurrent and it has been reported in three unrelated children with similar phenotypes (Mirzaa et al, 2016, Handoko et al. 2018). 
(A)

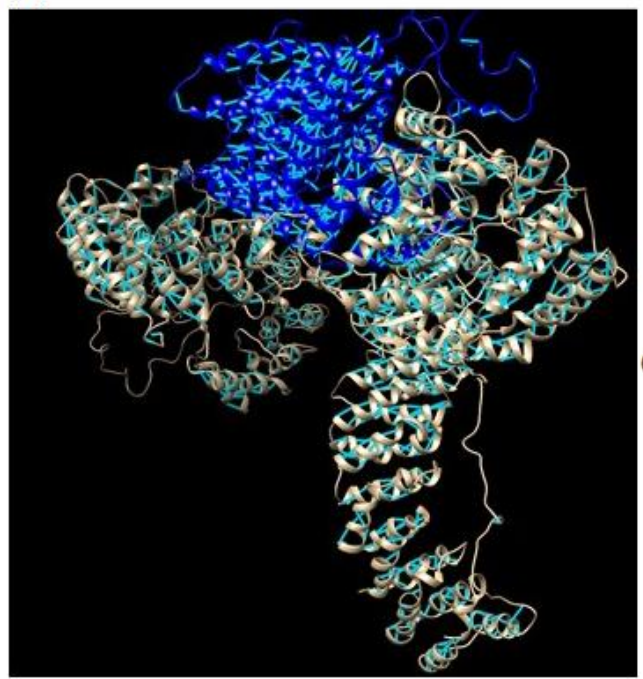

(B)

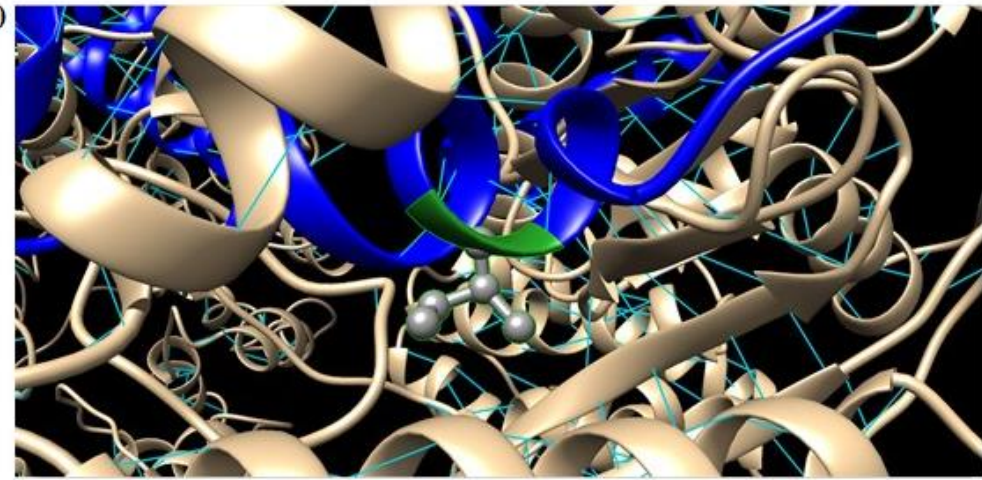

(C)

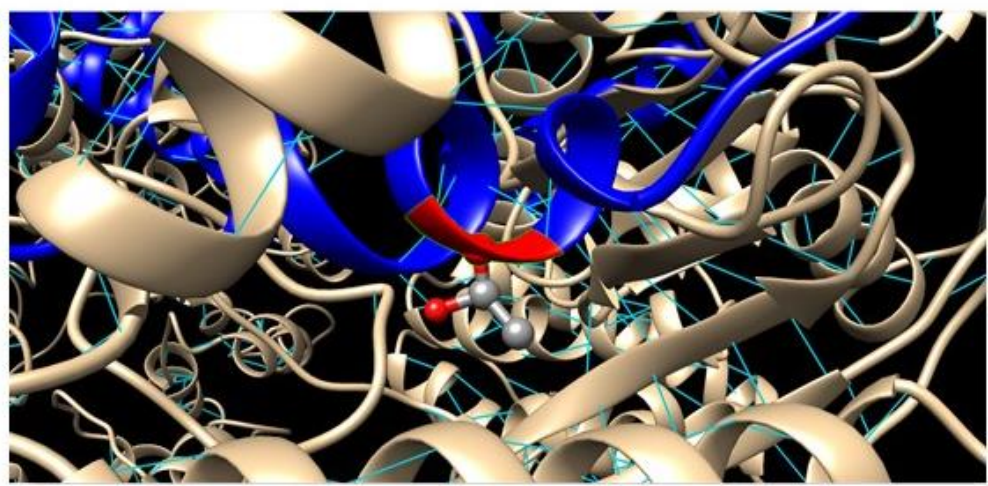

Figure 14: (A) mTOR protein structure modeled by SwissModel (https://swissmodel.expasy.org/).and analyzed with Chimera (https://www.cgl.ucsf.edu/chimera/).The substitution we found in Patient 2 causes the replacing of a polar-charged amino acid (Thr, B) with a non-polar-charged one (lle, C).

In our patient, the mutation was somatic and was present with different percentages of mosaicism in the different tissues we tested. Since we detected the mutation also in patient's fibroblasts, a cell line easily accessible, we decided to test the effectiveness of a novel potential mTOR pathway inhibitor in such cells.

To confirm that the mutation affected the regulation of mTOR pathway in patient's fibroblasts in response to nutrients deprivation, we evaluated the levels of P-RPS6 expression in cells incubated with HBSS, a balanced salt solution already used to induce starvation in fibroblasts (Marciano et al., 2018). Incubation in HBSS reduced mTOR activity in both control's and patient's cells, but patient's cells maintained an expression of P-RPS6 that was significantly higher than that observed in control's cells. This finding was consistent with an increased activation of the pathway caused by the gain-of-function effect of the mutation.

The role of the mTOR pathway in several malignancies has opened new opportunities and challenges regarding mTOR as a pharmacological target. Rapamycin and its derivatives (rapalogs) constitute the first generation of mTOR inhibitors, but they are associated with various adverse events (Lamming et al., 2013, Gyurus et al., 2011). Metformin, a widely prescribed antidiabetic drug, is emerging as a novel and effective mTOR inhibitor whose adverse effects are less severe than those of rapalogs. In addition, recent studies have demonstrated that early treatment with metformin prevented seizure onset and late treatment suppressed seizure frequency in FCD mice electroporated in utero with MTOR mutations identified in FCD patients. (Kim et al., 2019) Treating patient's and control's fibroblasts with metformin, we demonstrated that this treatment is able to revert mTOR pathway hyperactivation also in fibroblasts of patients carrying mutations 
in MTOR and that treatment with $5 \mathrm{mM}$ of metformin for 24 hours is sufficient to bring P-RPS6 expression in mutant cells at the levels observed in control cells. However, plasma concentrations of metformin in diabetic patients are estimated to be around $50 \mu \mathrm{M}$. Thus, in our experiments, we exposed fibroblasts to drug concentrations that are higher with respect to recommended therapeutic levels. On the other hand, in the ever-growing list of manuscripts on the anti-tumor effects of metformin, authors have exposed cell cultures to metformin concentrations ranging from 1 up to $100 \mathrm{mM}$ (Martin-Castillo et al., 2010), suggesting that 5$10 \mathrm{mM}$ of metformin can be used at least in preclinical models. Therefore, additional studies are needed to validate the effectiveness of metformin in reverting the phenotype caused by different mutations in mTOR pathway genes and to evaluate the optimal concentration for treating patients carrying such mutations.

\section{CONCLUSIONS}

NGS has considerably accelerated the identification of MCDs causing genes but it generates a large amount of variations that are difficult to be interpreted. The results we obtained in this $\mathrm{PhD}$ project point to the importance of associating NGS analysis with rapid and effective functional tests that allow validating the causative effect of the identified mutations. In addition, we demonstrated that for mTOR related MCDs, patients' fibroblasts may represent a good model to test novel pharmacological treatments and that metformin may be considered a novel and promising treatment for mTOR related MCDs. 


\section{BIBLIOGRAFY}

Abdollahi MR, Morrison E, Sirey T, Molnar Z, Hayward BE, et al: Mutation of the variant alpha-tubulin TUBA8 results in polymicrogyria with optic nerve hypoplasia. Am J Hum Genet 85: 737-744 (2009).

Alkuraya FS, Cai X, Emery C, Mochida GH, AlDosari MS, et al: Human mutations in NDE1 cause extreme microcephaly with lissencephaly [corrected]. Am J Hum Genet 88: 536-547 (2011).

Bahi-Buisson N, Poirier K, Fourniol F, Saillour Y, Valence S, et al: The wide spectrum of tubulinopathies: what are the key features for the diagnosis? Brain 137: 1676-1700 (2014).

Bahareh Rabbani, Mustafa Tekin and Nejat Mahdieh, The promise of whole-exome sequencing in medical Genetics, journal of Human Genetics (2014) 59, 5-1.

Barkovich AJ, Kjos BO: Schizencephaly: correlation of clinical findings with MR characteristics. AJNR Am J Neuroradiol 13: 85-94 (1992).

Barkovich AJ, Lindan CE: Congenital cytomegalovirus infection of the brain: imaging analysis and embryologic considerations. AJNR Am J Neuroradiol 15: 703-715 (1994).

Barkovich AJ, Guerrini R, Battaglia G, Kalifa G, N'Guyen T, et al: Band heterotopia: correlation of outcome with magnetic resonance imaging parameters. Ann Neurol 36: 609-617 (1994).

Barkovich AJ, Hevner R, Guerrini R: Syndromes of bilateral symmetrical polymicrogyria. AJNR Am J Neuroradiol 20: 1814-1821 (1999).

Barkovich AJ, Guerrini R, Kuzniecky RI, Jackson GD, Dobyns WB: A developmental and genetic classification for malformations of cortical development: update 2012. Brain 135:1348-1369 (2012).

Begoña Martin-Castillo, Alejandro Vazquez-Martin, Cristina Oliveras-Ferraros and Javier A. Menendez, Metformin and cancer, Cell Cycle 9:6, 10571064; March 15, 2010; Landes Bioscience.

Bielschowsky M: Über Mikrogyrie (in German). J Psychol Neurol 22: 1-47 (1916).

Bilgüvar K, Oztürk AK, Louvi A, Kwan KY, Choi M, et al: Whole-exome sequencing identifies recessive WDR62 mutations in severe brain malformations. Nature 467: 207-210 (2010).

Blümcke I, Thom M, Aronica E, Armstrong DD, Vinters HV, et al: The clinicopathologic spectrum of focal cortical dysplasias: a consensus classification proposed by an ad hoc Task Force of the ILAE Diagnostic Methods Commission. Epilepsia 52: 158-174 (2011).

Blumcke I, Spreafico R: An international consensus classification for focal cortical dysplasias. Lancet Neurol 10: 26-27 (2011).

Boycott KM, Flavelle S, Bureau A, Glass HC, Fujiwara TM, et al: Homozygous deletion of the very low density lipoprotein receptor gene causes autosomal recessive cerebellar hypoplasia with cerebral gyral simplification. Am J Hum Genet 77: 477-483 (2005).

Cappello S, Gray MJ, Badouel C, Lange S, Einsiedler M, et al: Mutations in genes encoding the cadherin receptor-ligand pair DCHS1 and FAT4 disrupt cerebral cortical development. Nat Genet 45: 1300-1308 (2013).

Caspi, M., Coquelle, F. M., Koifman, C., Levy, T., Arai, H., Aoki, J., Reiner, O. (2003). LIS1 missense mutations. Variable phenotypes result from unpredictable alterations in biochemical and cellular properties. Journal of Biological Chemistry, 278(40), 38740-38748.

Chabu C, Henegariu O, et al: Mutations in KATNB1 cause complex cerebral malformations by disrupting asymmetrically dividing neural progenitors. Neuron 84: 1226-1239 (2014).

Chang BS, Apse KA, Caraballo R, Cross JH, Mclellan A, et al: A familial syndrome of unilateral polymicrogyria affecting the right hemisphere. Neurology 66: 133-135 (2006)

Choo, A. Y., Yoon, S. O., Kim, S. G., Roux, P. P., and Blenis, J. (2008) Rapamycin differentially inhibits S6Ks and 4E-BP1 to mediate celltypespecific repression of mRNA translation. Proc. Natl. Acad. Sci. U.S.A. 105, 17414-17419.

Conti V, Carabalona A, Pallesi-Pocachard E, Parrini E, Leventer RJ, et al: Periventricular heterotopia in 6q terminal deletion syndrome: role of the C6orf70 gene. Brain 136: 3378- 3394 (2013)

Conti V, Pantaleo M, Barba C, Baroni G, Mei D, et al: Focal dysplasia of the cerebral cortex and infantile spasms associated with somatic 1q21.1-q44 duplication including the AKT3 gene. Clin Genet 88: 241-247 (2015).

Crino PB: Focal brain malformations: seizures, signaling, sequencing. Epilepsia 50 Suppl 9: 3-8 (2009).

Cushion TD, Dobyns WB, Mullins JG, Stoodley N, Chung SK, et al: Overlapping cortical malformations and mutations in TUBB2B and TUBA1A. Brain 136: 536-548 (2013).

D’Agostino MD, Bastos A, Piras C, Bernasconi A, Grisar T, et al: Posterior quadrantic dysplasia or hemiemimegalencephaly: a characteristic brain malformation. Neurology 62: 2214-2220 (2004).

D’Gama AM, Geng Y, Couto JA, Martin B, Boyle EA, et al: Mammalian target of rapamycin pathway mutations cause hemimegalencephaly and focal cortical dysplasia. Ann Neurol 77: 720-725 (2015)

De Rosa MJ, Secor DL, Barsom M, Fisher RS, Vinters HV: Neuropathologic findings in surgically treated hemimegalencephaly: immunohistochemical, morphometric, and ultrastructural study. Acta Neuropathol 84: 250-260 (1992). 
DeMyer W: Megalencephaly: types, clinical syndromes, and management. Pediatr Neurol 2: 321-328 (1986).

des Portes V, Francis F, Pinard JM, Desguerre I, Moutard ML, et al: doublecortin is the major gene causing X-linked subcortical laminar heterotopia (SCLH). Hum Mol Genet 7: 1063-1070 (1998).

Di Resta Chiara, Silvia Galbiati, Paola Carrera and Maurizio Ferrari Next-generation sequencing approach for the diagnosis of human diseases: open challenges and new opportunities, EJIFCC. 2018 Apr; 29(1): 4-14.

Dobyns WB, Mirzaa G, Christian SL, Petras K, Roseberry J, et al: Consistent chromosome abnormalities identify novel polymicrogyria loci in 1p36.3, 2p16.1-p23.1, 4q21.21-q22.1, 6q26-q27, and 21q2. Am J Med Genet A 146A:1637-1654 (2008).

Dobyns WB, Guerrini R, Leventer RL: Malformations of cortical development, in Swaiman KF, Ashwal S, Ferriero DM, Schor NF (eds): Swaiman's Pediatric Neurology: Principles and Practice, ed 5, pp 202-231 (Elsevier Saunders, Edinburgh 2012).

Ehninger et al., 2013, From genes to cognition in tuberous sclerosis: Implications for mTOR inhibitor-based treatment approaches. Neuropharmacology. 68:97-105.

Evrard P, De saint-georges P, Kadhim HJ, Gadisseux J-F. Pathology of prenatal encephalopathies. In: French J, editor. Child Neurology and developmental disabilities. Brookes: Baltimore, Paul H; 1989.

Fernández-Marmiesse Ana, Sofía Gouveia and María L. Couce, NGS Technologies as a Turning Point in Rare Disease Research, Diagnosis and Treatment, Curr Med Chem. 2018 Jan; 25(3): 404-432.

Fox JW, Lamperti ED, Ekşioğlu YZ, Hong SE, Feng Y, et al: Mutations in filamin 1 prevent migration of cerebral cortical neurons in human periventricular heterotopia. Neuron 21: 1315-1325 (1998).

Gleeson JG, Allen KM, Fox JW, Lamperti ED, Berkovic S, Scheffer I, Cooper EC, Dobyns WB, Minnerath SR, Ross ME, Walsh CA: Doublecortin, a brain-specific gene mutated in human X-linked lissencephaly and double cortex syndrome, encodes a putative signal-ing protein. Cell 92: 63-72 (1998)

Guerrini R. e Dobyns WB. (2014). Malformation of cortical development: Clinical features and genetic causes. Lancet Neurol. 13: 710-26.

Gleeson JG, Minnerath S, Kuzniecky RI, Dobyns WB, Young ID, Ross ME, Walsh CA: Somatic and germline mosaic mutations in the doublecortin gene are associated with variable phenotypes. Am J Hum Genet 67: 574-581 (2000b).

Golden AJ, Harding BN: Pathology and Genetics: Developmental Neurophatology (ISN Neuropath Press, Basel 2012).

Guerreiro MM, Andermann E, Guerrini R, Dobyns WB, Kuzniecky R, et al: Familial perisylvian polymicrogyria: a new familial syndrome of cortical maldevelopment. Ann Neurol 48: 39-48 (2000).

Guerrini R, Dubeau F, Dulac O, Barkovich AJ, Kuzniecky R, et al: Bilateral parasagittal parietooccipital polymicrogyria and epilepsy. Ann Neurol 41: 65-73 (1997)

Guerrini R, Moro F, Andermann E, Hughes E, D’Agostino D, et al: Nonsyndromic mental retardation and cryptogenic epilepsy in women with Doublecortin gene mutations. Ann Neurol 54: 30-37 (2003).

Guerrini R, Mei D, Sisodiya S, Sicca F, Harding B, et al: Germline and mosaic mutations of FLN1 in men with periventricular heterotopia. Neurology 63: 51-56 (2004).

Guerrini R, Filippi T: Neuronal migration disorders, genetics, and epileptogenesis. J Child Neurol 20: 287-299 (2005).

Guerrini and Dobyns, 2014 (Barkovich, A.J Kuzniecky, Jackson, G.D Guerrini, Dobyns, W., 2005. A developmental and genetic classification for malformations of cortical development. Neurology, 65(12), pp.1873-1887

Guerrini R, Dobyns W, Barkovich A: Abnormal development of the human cerebral cortex: genetics, functional consequences and treatment options. Trends Neurosci 31: 154-162 (2008).

Guerrini R, Barba C: Malformations of cortical development and aberrant cortical networks: epileptogenesis and functional organization. J Clin Neurophysiol 27: 372-379 (2010).

Guerrini R, Parrini E: Neuronal migration disorders. Neurobiol Dis 38: 154-166 (2010).

Guerrini R, Mei D, Cordelli DM, Pucatti D, Franzoni E, Parrini E: Symmetric polymicrogyria and pachygyria associated with TUBB2B gene mutations. Eur J Hum Genet 20: 995-998 (2012).

Guerrini R, Dobyns WB: Malformations of cortical development: clinical features and genetic causes. Lancet Neurol 13: 710-726 (2014).

Guerrini R, Duchowny M, Jayakar P, Krsek P, Kahane P, et al: Diagnostic methods and treatment options for focal cortical dysplasia. Epilepsia 56: 1669-1686 (2015).

Gyurus E, Kaposztas Z, Kahan BD. Sirolimus therapy predisposes to new-onset diabetes mellitus after renal transplantation: a long-term analysis of various treatment regimens. Transplant Proc. 2011;43(5):1583-1592.

Hara et al. Raptor, a binding partner of target of rapamycin (TOR), mediates TOR action. Cell 2002; 110: $177-89$.

Hilburger AC, Willis JK, Bouldin E, Henderson- Tilton A: Familial schizencephaly. Brain Dev 15: 234-236 (1993). 
Hirotsune S, Fleck MW, Gambello MJ, Bix GJ, Chen A, et al: Graded reduction of Pafah1b1 (Lis1) activity results in neuronal migration defects and early embryonic lethality. Nat Genet 19: 333-339 (1998).

Hong SE, Shugart YY, Huang DT, Shahwan SA, Grant PE, et al: Autosomal recessive lissencephaly with cerebellar hypoplasia is associated with human RELN mutations. Nat Genet 26: 93-96 (2000).

Hudes G et al. Temsirolimus, interferon alfa, or both for advanced renal-cell carcinoma. N Engl J Med 2007; 356: $2271-81$.

Jaglin XH, Poirier K, Saillour Y, Buhler E, Tian G, et al: Mutations in the beta-tubulin gene TUBB2B result in asymmetrical polymicrogyria. Nat Genet 41: 746-752 (2009).

Keays DA, Tian G, Poirier K, Huang G J, SieboldC, et al: Mutations in alpha-tubulin cause abnormal neuronal migration in mice and lissencephaly in humans. Cell 128: 45-57 (2007).

Kheradmand Kia S, Verbeek E, Engelen E, Schot R, Poot RA, et al: RTTN mutations link primary cilia dunction to organization of the human cerebral cortex. Am J Hum Genet 91:533-540 (2012).

Kielar M, Tuy FP, Bizzotto S, Lebrand C, de Juan Romero C, et al: Mutations in Eml1 lead to ectopic progenitors and neuronal heterotopia in mouse and human. Nat Neurosci 17: 923-933 (2014).

Kim et al., Brain somatic mutations in MTOR reveal translational dysregulations underlying intractable focal epilepsy J Clin Invest. 2019.

Korman et al., Early seizure onset and dysplastic lesion extent independently disrupt cognitive networks.Neurology. 81:745-51. 2013.

Kumar RA, Pilz DT, Babatz TD, Cushion TD, Harvey K, et al: TUBA1A mutations cause wide spectrum lissencephaly (smooth brain) and suggest that multiple neuronal migration pathways converge on $\alpha$ tubulins. Hum Mol Genet 19: 2817-2827 (2010).

Kuzniecky RI, Andermann F, Guerrini R: Congenital bilateral perisylvian syndrome: study of 31 patients. The CBPS Multicenter Collaborative Study. Lancet 341: 608-612 (1993).

Lamming et al. 2013, Rapalogs and mTOR inhibitors as anti-aging therapeutics, J Clin Invest. 2013;123(3):980-989.

Lee JH, Huynh M, Silhavy JL, Kim S, Dixon-Salazar T, et al: De novo somatic mutations in components of the PI3K-AKT3-mTOR pathway cause hemimegalencephaly. Nat Genet 44: 941-945 (2012).

Lefort C. and M. Kim, Human T Lymphocyte Isolation, Culture and Analysis of Migration In Vitro, J Vis Exp. 2010 ; (40): 2017.

Leventer, R. J., Cardoso, C., Ledbetter, D. H., \& Dobyns, W. B. (2001). LIS1 missense mutations cause milder lissencephaly phenotypes including a child with normal IQ. Neurology, 57(3), 416-422.

Leventer RJ, Jansen A, Pilz DT, Stoodley N, Marini C, et al: Clinical and imaging heterogeneity of polymicrogyria: a study of 328 patients. Brain 133: 1415-1427 (2010).

Lim JS, Kim WI, Kang HC, Kim SH, Park AH, et al: Brain somatic mutations in MTOR cause focal cortical dysplasia type II leading to intractable epilepsy. Nat Med 21: 395-400 (2015).

Lu J, Tiao G, Folkerth R, Hecht J, Walsh C, Sheen V: Overlapping expression of ARFGEF2 and Filamin A in the neuroependymal lining of the lateral ventricles: insights into the cause of periventricular heterotopia. J Comp Neurol 494: 476-484 (2006).

Ma XM et al., Molecular mechanisms of mTOR-mediated translational control. Nat Rev Mol Cell Biol 2009; 10: 30-18.

Magen D, Ofir A, Berger L, Goldsher D, Eran A, et al: Autosomal recessive lissencephaly with cerebellar hypoplasia is associated with a loss offunction mutation in CDK5. Hum Genet 134: 305-314 (2015).

Marsan1 \& Stéphanie Baulac, Mechanistic target of rapamycin (mTOR) pathway, focal cortical dysplasia and epilepsy. Neuropathol Appl Neurobiol. $2018 \mathrm{Feb}$;44(1):6-17.

Matsumoto N, Leventer RJ, Kuc JA, Mewborn SK, Dudlicek LL, et al: Mutation analysis of the DCX gene and genotype/phenotype correlation in subcortical band heterotopia. Eur J Hum Genet 9: 5-12 (2001).

Maureen Handoko, Lisa T. Emrick1, Jill A. Rosenfeld, Xia Wang, Alyssa A. Tran, Alicia Turner, John W. Belmont, Brendan H. Lee, Carlos A. Bacino, Hsiao-Tuan Chao. Recurrent mosaic MTOR c.5930C > T (p.Thr1977Ile) variant causing megalencephaly, asymmetric polymicrogyria, and cutaneous pigmentary mosaicism: Case report and review of the literature. Am J Med Genet A, 2018.

Mei D, Lewis R, Parrini E, Lazarou LP, Marini C, et al: High frequency of genomic deletion - and duplication - in the LIS1 gene in lissencephaly: implications for molecular diagnosis. J Med Genet 45: 355-361 (2008).

Mineyko A1, Doja A, Hurteau J, Dobyns WB, Das S, Boycott KM. A novel missense mutation in LIS1 in a child with subcortical band heterotopia and pachygyria inherited from his mildly affected mother with somatic mosaicism. J Child Neurol. 2010 Jun;25(6):738-41.

Mirzaa GM, Conway RL, Gripp KW, Lerman-Sagie T, Siegel DH, et al: Megalencephaly-capillary malformation (MCAP) and megalencephalypolydactyly-polymicrogyria-hydrocephalus (MPPH) syndromes: two closely related disorders of brain overgrowth and abnormal brain and body morphogenesis. Am J Med Genet A 158A:269-291 (2012).

Mirzaa GM, Ashwal S, Dobyns WB:Disorders of brain size, in Swaiman KF, Ashwal S, Ferriero DF, Schor NF (eds): Swaiman's Pediatric Neurology: Principles and Practice, ed 5, pp173-201 (Elsevier Saunders, Edinburgh 2012). 
Mirzaa GM, Conti V, Timms AE, Smyser CD, Ahmed S, et al: Characterisation of mutations of the phosphoinositide-3-kinase regulatory subunit, PIK3R2, in perisylvian polymicrogyria: a next-generation sequencing study. Lancet Neurol 14: 1182-1195 (2015).

Mirzaa et al, Association of MTOR Mutations With Developmental Brain Disorders, Including Megalencephaly, Focal Cortical Dysplasia, and Pigmentary Mosaicism. JAMA Neurol. 2016 Jul 1;73(7):836-845.

Mishra-Gorur K, Çağlayan AO, Schaffer AE, Chabu C, Henegariu O, et al: Mutations in KATNB1 cause complex cerebral malformations by disrupting asymmetrically dividing neural progenitors. Neuron 84: 1226-1239 (2014).

Motzer RJ et al. Efficacy of everolimus in advanced renal cell carcinoma: a double-blind, randomised, placebo-controlled phase III trial. Lancet 2008; 372: 449-56.

Nellist M, Brouwer RW, Kockx CE, van Veghel-Plandsoen M, Withagen-Hermans C, et al: Targeted next generation sequencing reveals previously unidentified TSC1 and TSC2 mutations. BMC Med Genet 16: 10 (2015).

Packard AM, Miller VS, Delgado MR: Schizencephaly: correlations of clinical and radiologic features. Neurology 48: 1427-1434 (1997).

Parrini E, Ramazzotti A, Dobyns WB, Mei D, Moro F, et al: Periventricular heterotopia: phenotypic heterogeneity and correlation with Filamin A mutations. Brain 129: 1892-1906 (2006).

Parrini E, Conti V, Dobyns W, Guerrini R: Genetic Basis of Brain Malformations 2016. Mol Syndromol, DOI: 10.1159/000448639.

Parrini, E., Marini, C., Mei, D., Galuppi, A., Cellini, E., Pucatti, D., ...Sterebova, K. (2017). Diagnostic targeted resequencing in 349 patientswith drug-resistant pediatric epilepsies identifies causative mutationsin 30 different genes. Human Mutation, 38(2), $216-225$.

Peterson et al. DEPTOR is an mTOR inhibitor frequently overexpressed in multiple myeloma cells and required for their survival. Cell 2009; 137 : $873-86$.

Piao X, Hill RS, Bodell A, Chang BS, Basel-Vanagaite L, et al: G protein-coupled receptor-dependent development of human frontal cortex. Science 303: 2033-2036 (2004).

Pisano T, Barkovich AJ, Leventer RJ, Squier W, Scheffer IE, et al: Peritrigonal and temporooccipital heterotopia with corpus callosum and cerebellar dysgenesis. Neurology 79: 1244-1251 (2012).

Poduri A, Evrony GD, Cai X, Elhosary PC, Beroukhim R, et al: Somatic activation of AKT3 causes hemispheric developmental brain malformations. Neuron 74: 41-48 (2012).

Poirier K, Lebrun N, Broix L, Tian G, Saillour Y, et al: Mutations in TUBG1, DYNC1H1, KIF5C and KIF2A cause malformations of cortical development and microcephaly. Nat Genet 45: 639-667 (2013).

Ran Marciano, Gabriel Leprivier \& Barak Rotblat, Puromycin labeling does not allow protein synthesis to be measured in energy-starved cells. Cell Death \& Disease volume 9, Article number: 39 (2018).

Reiner O, Carrozzo R, Shen Y, Wehnert M, Faustinella F, et al: Isolation of a Miller-Dieker lissencephaly gene containing G protein betasubunit- like repeats. Nature 364: 717-721 (1993).

Rivière JB, van Bon BW, Hoischen A, Kholmanskikh SS, O'Roak BJ, et al: De novo mutations in the actin genes ACTB and ACTG1 cause Baraitser-Winter syndrome. Nat Genet 44: 440-4444, S1-2 (2012a).

Rivière JB, Mirzaa GM, O’Roak BJ, Beddaoui M, Alcantara D, et al: De novo germline and postzygotic mutations in AKT3, PIK3R2 and PIK3CA cause a spectrum of related megalencephaly syndromes. Nat Genet 44: 934-940 (2012b).

Robert A. Saxton and David M. Sabatin, mTOR Signaling in Growth, Metabolism, and Disease, Cell. 2017 Mar 9; 168(6): 960-976.

Robin NH, Taylor CJ, McDonald-McGinn DM, Zackai EH, Bingham P, et al: Polymicrogyria and deletion 22 q11.2 syndrome: window to the etiology of a common cortical malformation. Am J Med Genet A 140: 2416-2425 (2006).

Saillour, Y., Carion, N., Quelin, C., Leger, P.-L., Boddaert, N., Elie, C., Bahi-Buisson, N. (2009). LIS1-related isolated lissencephaly: Spectrum of mutations and relationships with malformation severity. Archives of Neurology, 66(8), 1007-1015.

Salamon N, Andres M, Chute DJ, Nguyen ST,Chang JW, et al: Contralateral hemimicrencephaly and clinical-pathological correlations in children with hemimegalencephaly. Brain 129: 352-365 (2006).

Santos NF, Secolin R, Brandão-Almeida IL, Silva MS, Torres FR, et al: A new candidate locus for bilateral perisylvian polymicrogyria mapped on chromosome Xq27. Am J Med Genet A 146A:1151-1157 (2008).

Sapir, T., Elbaum, M., \& Reiner, O. (1997). Reduction of microtubule catastrophe events by LIS1, platelet-activating factor acetylhydrolase subunit. The EMBO Journal, 16(23), 6977-6984.

Sarbassov et al. Rictor, a novel binding partner of mTOR, defines a rapamycin-insensitive and raptor-independent pathway that regulates the cytoskeleton. Curr Biol 2004; 14: 1296-302.

Sheen VL, Ganesh VS, Topcu M, Sebire G, Bodell A, et al: Mutations in ARFGEF2 implicate vesicle trafficking in neural progenitor proliferation and migration in the human cerebral cortex. Nat Genet 36: 69-76 (2004).

Sicca F, Kelemen A, Genton P, Das S, Mei D, et al: Mosaic mutations of the LIS1 gene cause subcortical band heterotopia. Neurology 61: $1042-1046$ (2003). 
Sim JC, Scerri T, Fanjul-Fernández M, Riseley JR, Gillies G, et al: Familial cortical dysplasia caused by mutation in the mTOR regulator NPRL3. Ann Neurol 79: 132-137 (2015).

Tinkle BT, Schorry EK, Franz DN, Crone KR, Saal HM: Epidemiology of hemimegalencephaly: a case series and review. Am J Med Genet A139: 204-211 (2005).

Verloes A, Di Donato N, Masliah-Planchon J, Jongmans M, Abdul-Raman OA, et al: Baraitser- Winter cerebrofrontofacial syndrome: delineation of the spectrum in 42 cases. Eur J Hum Genet 23: 292-301 (2015).

Villard L, Nguyen K, Cardoso C, Martin CL, Weiss AM, et al: A locus for bilateral perisylvian polymicrogyria maps to Xq28. Am J Hum Genet 70: 1003-1008 (2002).

Winder WW, Hardie DG: The AMP-activated protein kinase, a metabolic master switch: possible roles in type 2 diabetes. Am J Physiol277 : E1E10,1999.

Wang D, Zeesman S, Tarnopolsky MA, Nowaczyk MJ: Duplication of AKT3 as a cause of macrocephaly in duplication 1q43q44. Am J Med Genet A 161: 2016-2019(2013).

Yang, H., \& Wang, K. (2015). Genomic variant annotation and prioritizationwith ANNOVAR and wANNOVAR. Nature Protocols, 10(10), 15561566 .

Yakovlev PI, Wadsworth RC: Schizencephalies; a study of the congenital clefts in the cerebral mantle; clefts with hydrocephalus and lips separated. J Neuropathol Exp Neurol 5: 169-206 (1946).

Zhou G, Myers R, Li Y et al. Role of AMP-activated protein kinase in mechanismof metformin action. J Clin Invest 2001; 108: 1167-1174. 